Florida International University

FIU Digital Commons

FIU Electronic Theses and Dissertations

University Graduate School

11-9-1995

\title{
Hospice nurses' attitudes on active voluntary euthanasia
}

Belinda Arjona Godfrey

Florida International University

Follow this and additional works at: https://digitalcommons.fiu.edu/etd

Part of the Nursing Commons

\section{Recommended Citation}

Godfrey, Belinda Arjona, "Hospice nurses' attitudes on active voluntary euthanasia" (1995). FIU Electronic Theses and Dissertations. 3944.

https://digitalcommons.fiu.edu/etd/3944

This work is brought to you for free and open access by the University Graduate School at FIU Digital Commons. It has been accepted for inclusion in FIU Electronic Theses and Dissertations by an authorized administrator of FIU Digital Commons. For more information, please contact dcc@fiu.edu. 


\title{
FLORIDA INTERNATIONAL UNIVERSITY \\ Miami, Florida
}

\author{
HOSPICE NURSES' ATTITUDES ON \\ ACTIVE VOLUNTARY EUTHANASIA
}

\begin{abstract}
A thesis submitted in partial satisfaction of the requirements for the degree of
\end{abstract}

MASTERS OF SCIENCE

IN

NURSING

by

Belinda Arjona Godfrey

1995 
To: Dr. Linda Simunek

School of Nursing

This thesis written by Belinda Arjona Godfrey, and entitled HOSPICE NURSES'

ATTITUDES ON ACTIVE VOLUNTARY EUTHANASIA, having been approved in respect to style and intellectual content, is referred to you for judgement.

We have read this thesis and recommend that it be approved.

Divina Grossman

Martha Pelaez

Date of Defense: $11-9$ - 95

Linda Simunek

The thesis of Belinda Arjona Godfrey is approved.

Dean Linda Simunek

School of Nursing

Dr. Richard L. Campbell

Dean of Graduate Studies

Florida International University, 1995 
I dedicate this thesis to my husband, William. Without his confidence, patience, understanding, support, and most of all, love, the completion of this work would not have been possible. 


\section{ACKNOWLEDGEMENTS}

I wish to thank the members of my committee for their guidance, patience, and support. I also want to thank others who provided me with guidance, assistance and support with this thesis: Linda Washington, Dr. Georgie Labadie, Dr. Paulette Johnson and Dr. Dierdra Krouse.

A special thanks to my father, Nicholas and my sister, Bonnie, for having confidence in me throughout the years, and especially for giving me their love and friendship. Thanks to my mother, Magui, for all the unconditional love she has given to me all my life. And thanks to all my friends for being behind me all the way. 


\author{
ABSTRACT OF THE THESIS \\ HOSPICE NURSES' ATTITUDES ON ACTIVE VOLUNTARY \\ EUTHANASIA \\ by \\ Belinda Arjona Godfrey \\ Florida International University, 1995 \\ Dean Linda Simunek, Major Professor
}

Active voluntary euthanasia is one of the most controversial issues in the nursing and legal systems today. The purpose of this study was to explore hospice nurses' attitudes on active voluntary euthanasia (AVE). One hundred useable questionnaires were collected, for a response rate of $33 \%$. The questionnaires included demographic data, four vignettes which described a patient care situation and possible responses to AVE, questions on awareness of organizations and legislation that promote legalization of AVE, and questions on adequate pain relief. The findings revealed fifty - three per cent of the nurses supported AVE. Eighty - three per cent of the nurses would not administer the medication that would cause death. Also, there were significant relationships between the nurses' age, religion and educational level and their responses. 


\section{TABLE OF CONTENTS}

CHAPTER

PAGE

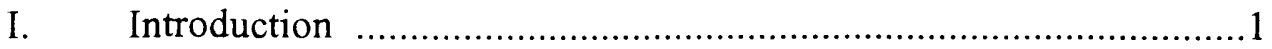

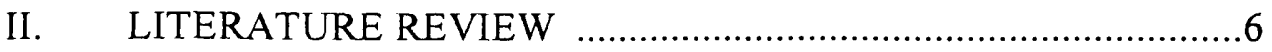

Humanitarian and Utilitarian Positions .............................6

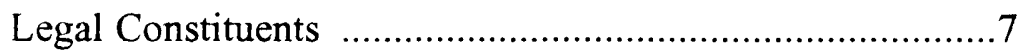

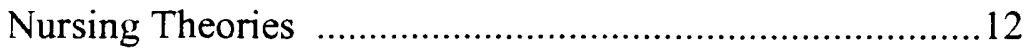

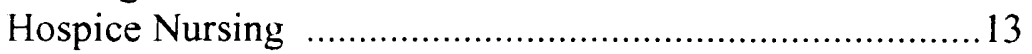

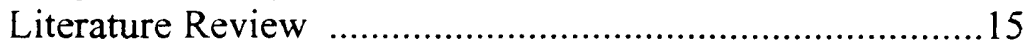

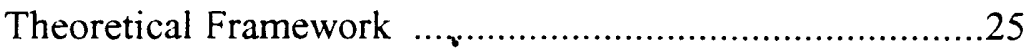

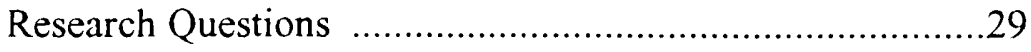

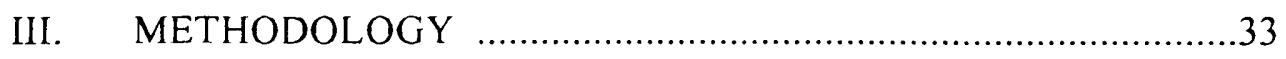

Approach and Design ............................................................

Sample and Sampling Method ...........................................33

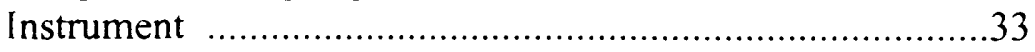

Data Collection Procedures ............................................ 35

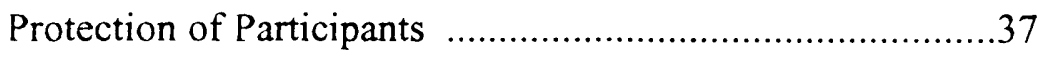

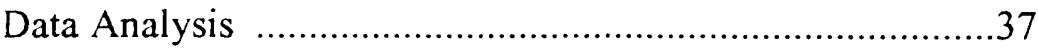

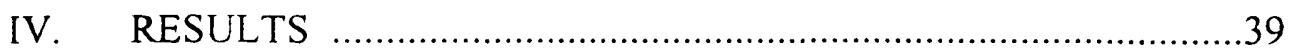

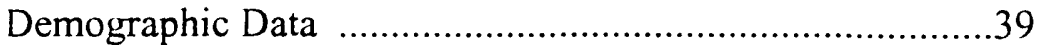

Research Question 1 ..................................................41

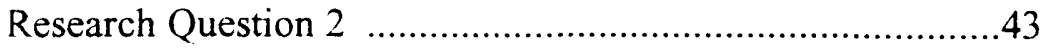

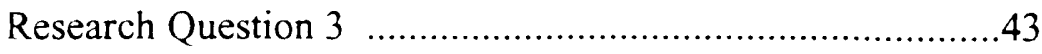

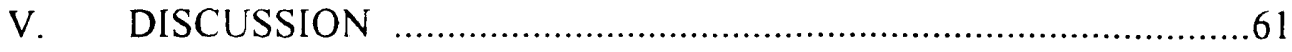

Discussion of Findings ………………..........................61

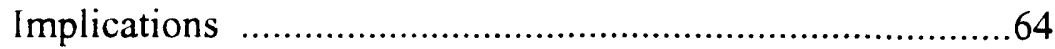

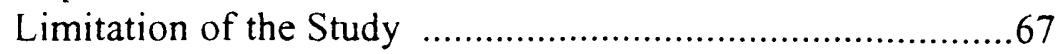

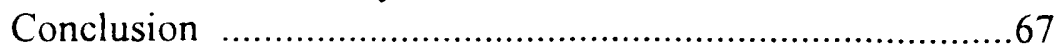

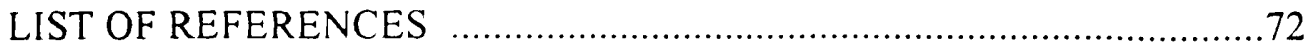

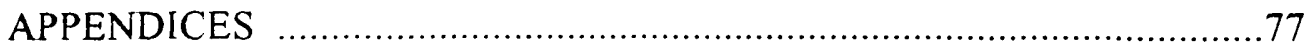




\section{LIST OF TABLES}

\section{TABLE}

I Schematic on the Nurses Autonomy With Issues on Euthanasia .....

II Schematic of Nurses Autonomous (Professional) Decision on Euthanasia as if it Were Legal

III Schematic of Nurses Autonomous (Personal) Decision on Euthanasia as if it Were Legal

IV Frequency and Percentage Distribution of Respondents' Gender, Age, Education and Religion

$\mathrm{V} \quad$ Average response of the nurses to vignette 1 through 4

VI Nurses responses on legalization of euthanasia

VII Nurses Responses to Vignette 3

VIII Relationship Between Age and Nurses Responses to Vignette 1

IX Relationship Between Age and Nurses Responses to Vignette 2 ....

X Relationship Between Age and Nurses Responses to Vignette 3 .....

XI Relationship Between Age and Nurses Responses to Vignette 4 .....

XII Relationship of Nurses' Age and Response to Legalization of

PAD

XIII Relationship Between Age and Nurses Responses to Adequate Pain Relief

XIV Analysis of variance of age and mean pain relief

XV Relationship of Nurses' Religion and responses to Vignette 1

XVI Relationship Between Nurses' Religion and Responses to Vignette 2 
XVII Relationship Between the Nurses' Religion and their Responses to Vignette 3

XVIII Relationship of Nurses' Religion and their Responses to Vignette 4

XIX Relationship of Nurses' Religion and Responses to Legalization of PAD

XX Relationship Between Nurses' Religion and Their Response to Adequate Pain Relief

XXI Relationship Between Nurses' Educational Level and Their Response to Vignette 1

XXII Relationship Between Nurses' Educational Level and Their Response to Vignette 2

XXIII Relationship Between Nurses' Educational Level and Their Response to Vignette 3

XXIV Relationship Between Nurses' Educational Level and Their Response to Vignette 4

XXV Relationship Between Nurses' Educational Level and Response to Legalization of PAD

XXVI Relationship Between the Nurses' Educational Level and Their Response to Adequate Pain Relief 


\section{LIST OF APPENDICES}

APPENDIX PAGE

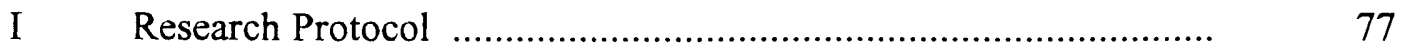

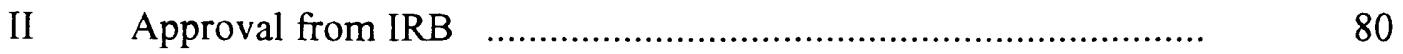

III Letter From Anne Young, RN, EdD. ......................................

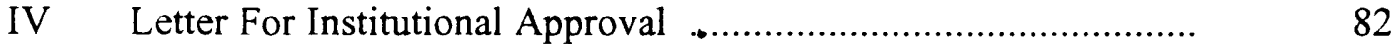

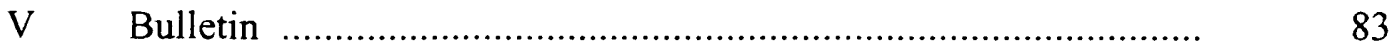

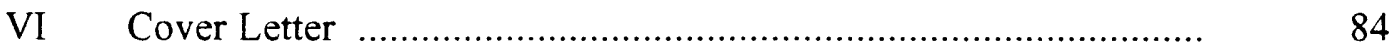

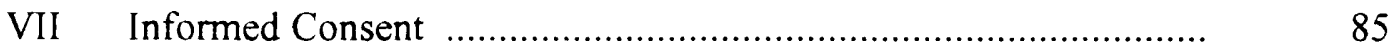

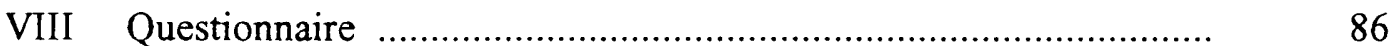

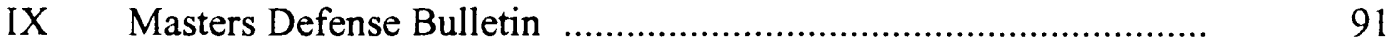

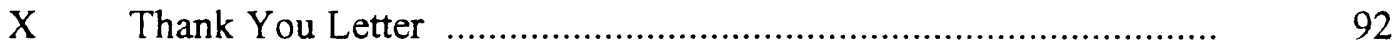




\section{CHAPTER I:}

\section{INTRODUCTION}

Recent advances in medical technology have left the nursing and medical healthcare professionals to debate the moral justifiability of the withdrawal of life sustaining interventions or the use of those interventions to prolong life (Young, Volker, Rieger, and Thorpe, 1993). This debate goes beyond the strict confines of science and encompasses the personal, moral, religious, cultural and philosophical beliefs of the nursing professional. While medical interventions can prolong physical life, they cannot guarantee restoration of the health of patients, nor are they able to alleviate the suffering of the families and friends of the patient. In today's society, $85 \%$ of deaths occur in the hospital and approximately, $75 \%$ of these deaths involve elective withdrawal of some type of life - sustaining treatment (Coyle, 1992). The voluntary withdrawal of life sustaining treatment is referred to as passive voluntary euthanasia.

The standard view of the morality of euthanasia is that it is morally acceptable under specifiable conditions but not lawfully acceptable. The standard view is clearly seen in the 1983 statement of the American Nursing Association (ANA) in the code for nurses which states that:

Nurses are morally obligated to respect human existence and the individuality of all persons who are the recipients of nursing actions. Nurses therefore must take all reasonable means to protect and preserve human life when there is hope of recovery or reasonable hope of benefit 
from life - prolonging treatment.

This respect extends to all who require the services of the nurse for the promotion

of health, the prevention of illness, the restoration of health, the alleviation of suffering, and the provision of supportive care of the dying.

The nurse does not act deliberately to terminate the life of any person.

However, active voluntary euthanasia has already been legalized in the state of Oregon and attempts for legalization are on their way in Washington State and California. The ANA does not give consent for nurses to participate in active voluntary euthanasia at this time. If active voluntary euthanasia becomes a right of the patient throughout the United States, the ANA may have to re - evaluate their standards and codes for nurses to follow. If these standards and codes are changed, nurses may find themselves at an impasse with active voluntary euthanasia, because of their own moral convictions.

\section{PURPOSE:}

The purpose of this study is to explore and describe the attitudes of hospice nurses towards active voluntary euthanasia (AVE) or physician assisted suicide (PAS).

\section{PROBLEM STATEMENT:}

Do hospice nurses support or reject active voluntary euthanasia and are they willing to be an active participant? 


\section{SPECIFIC PROBLEMS:}

The following questions are the basis for this study:

1. What are the attitudes of hospice nurses towards active voluntary euthanasia or physician - assisted suicide?

2. To what extent are hospice nurses willing to participate in active voluntary euthanasia or physician - assisted suicide?

3. To determine the relationship between hospice nurses demographic characteristics (age, religion, education) and their attitudes towards active voluntary euthanasia or physician - assisted suicide / dying.

\section{VARIABLES:}

Independent variables are the hospice nurses. The dependant variables are the hospice nurses support or rejections of active voluntary euthanasia and their participation. The nurses age, religion, and education will be accounted for in the study to determine any significant correlations.

\section{DEFINITION OF TERMS:}

1. Active voluntary euthanasia: a procedure demonstrated by administering a lethal drug, by a physician or a designee of the physician, to a competent person who has given verbal or written informed consent. Active voluntary euthanasia is a procedure only offered to a competent individual who has a terminal disease that is accompanied with a long and enduring death. Examples: terminal cancer, AIDS, early Alzheimer's.

2. Adult: any person over eighteen years of age. 
3. Competent: a person who is oriented to time, place, and person. A person who is able to comprehend treatment options and outcomes of these options.

4. Hospice nurses: nurses who care for terminally ill patients. These nurses provide patients with palliative care such as keeping the patient comfortable (pain relief) and support services such as assisting the patient and the family with their spiritual, social and economic needs.

5. Physician - assisted dying: a procedure demonstrated by administering a lethal drug, by a physician or a designee of the physician, to a competent person who has given verbal or written informed consent. Physician - assisted dying is a procedure only offered to a competent, terminally ill individuals.

6. Physician - assisted suicide: a procedure demonstrated by administering a lethal drug, by a physician or a designee of the physician, to a competent person, with a terminal disease, who has given verbal or written informed consent. For the purpose of this study the terms active voluntary euthanasia (AVE), physician - assisted dying (PAD) and physician assisted suicide (PAS) are interchangeable.

7. Terminally ill: a person with a disease that has been given the prognosis of six months or less confirmed by two physicians.

\section{SIGNIFICANCE:}

Nurses are closer to illness, death and dying experiences than most other health professionals. Nurses work in close proximity to their patients and patients frequently relate their beliefs and values to these nurses because they are willing to listen. Nurses 
have a unique perspective especially on the issue of active euthanasia. Their attitudes toward the right to die are influenced by what they are taught to value and their cultures. "Nursing education socializes the student to see patients holistically and act as an advocate in the patient's best interest, to be an advocate for a patient who wants to be allowed to die may be a real problem for a nurse whose values conflict with the patient's values" (Wold, 1992).

Limited studies and research have been done on nurses' attitudes toward active voluntary euthanasia. The studies that were done were limited to international countries, i. e. Japan, Netherlands and Australia. Only one study was done on American nurses and this study focused on oncology nurses.

Hospice nurses and their beliefs on active voluntary euthanasia has not been studied in the United States. Nurses in the hospice setting encounter death and dying on a regular basis. The United States is a melting pot of different cultures and nurses in this country come from different backgrounds, cultures and religions. Active euthanasia is fast becoming a maze that nurses must navigate, balancing their own moral convictions, their professions' guidelines and their patients' wishes. Nurses' attitudes toward active voluntary euthanasia should, therefore, be further explored within the United States. 


\section{CHAPTER II:}

\section{LITERATURE REVIEW}

\section{HUMANITARIAN AND UTILITARIAN POSITIONS:}

The argument for the legitimacy of euthanasia accentuates the consideration of humaneness. The humanitarian view appeals to the primacy of individual autonomy. The two basic arguments for the morality of voluntary euthanasia according to Mappes and Zembaty are:

1. "It is cruel and inhumane to refuse the plea of a terminally ill person that his or her life be mercifully ended in order to avoid future suffering and indignity."

2. "Individual choice should be respected to the extent that it does not result in harm to others" (Mappes \& Zembaty, 1991).

Proponents for mercy killing believe that no one should have to endure relentless pain (Haddad, 1991).

The two basic arguments against the legitimacy of mercy killing are the sanctity of life view and the utilitarian view. The sanctity of life view simply states that "all human lives, regardless of their quality or kind, are equally valuable and inviolable" (Kuhse and Singer, 1898). Utilitarians believe that euthanasia for any reason would do more harm than good in society. Once active euthanasia is permitted, they reason, a delineation of related circumstances may lead to the abusive killing of frail elderly, handicapped newborns or useless members of the society (Haddad, 1991). Voluntary 
euthanasia could inevitably lead to abusive social practices.

\section{LEGAL CONSIDERATIONS:}

Euthanasia has been extensively debated in the legal system. The most recent case being that of Dr. Jack Kavorkian, who has invented and utilized an apparatus to allow patients to painlessly end their own lives. After several court cases, Kavorkian was cleared of all murder charges but his license to practice medicine was revoked.

"Cruzan vs. Director Missouri Department of Health," also tested euthanasia in the legal arena. The parents of Nancy Cruzan urged the Court to discontinue nutrition and hydration to their daughter. After much debate, the feeding tube was removed and she died 12 days later (Anderson \& Caddell, 1993). The United States Supreme Court held that gastrostomy tubes (GT) and other invasive methods for receiving nutrition (central venous line - hyperalimentation and lipids) are treatments which competent persons have the right to refuse (passive voluntary euthanasia). The case of Nancy Cruzan was the pre-requisite for the enactment of the Patient Self Determination Act by Congress.

The Patient Self Determination Act (PSDA) requires hospitals, Health Management Organizations (HMO) and home health agencies who receive remuneration from Medicaid or Medicare to provide written information of the patient's right to refuse medical treatment. The right of patients to have legal advance directives went into effect in 199l (Wold, 1992). Advance directives provide the best means for a patient to ensure that their wishes are respected. Two types of advance directives are living wills and 
powers of attorney. Living wills were developed in 1968 (Harron, Burnside \& Beauchamp, 1983) but it was not until 1991 that hospitals, HMO's and home health agencies became legally responsible for honoring the living wills of dying patient's.

In the State of Florida, the Life Prolonging Procedure Act was enacted in 1990. This act authorizes withholding or withdrawal of tube feeding. The medical requirement insists that the attending physician and another physician determine that the patient is terminally ill and that life - sustaining treatments would only artificially prolong dying and that death is imminent (Nurse's Handbook of Laws and Ethics, 1992).

Florida statute, s765.309 states that:

(1) Nothing in this chapter shall be construed to authorize, or approve mercy killing euthanasia, or to permit any affirmative or deliberate act or omission to end the life other than to permit the natural process of dying.

(2) The withholding or withdrawal of life - prolonging procedures from a patient in accordance with any provisions of this chapter does not, for any purpose, constitute a suicide.

The State of Florida also developed a Patient Bill of Rights and Responsibilities. In this statute the health care provider and health care facility are required to recognize the rights of the patient while they are receiving medical care. It also states that the patient is to respect the health care provider and health care facility's right to expect certain behavior on the part of the patient. The following is a summary of the Florida 
statute 381.026; Patient's Bill of Rights and Responsibilities of 1992:

A patient has the right to be treated with courtesy and respect, with appreciation of his individual dignity, and with protection of his need for privacy.

A patient has the right to a prompt and reasonable response to questions and requests.

A patient has the right to know who is providing medical services and who is responsible for his care.

A patient has the right to know what patient support services are available, including whether an interpreter is available if he does not speak English.

A patient has a right to know what rules and regulations apply to his conduct.

A patient has the right to be given by his health care provider information concerning diagnosis, planning course of treatment, alternatives, risks, and prognosis.

A patient has the right to refuse any treatment, except as otherwise provided by law.

A patient has the right to be given, upon request, full information and necessary counseling on the availability of known financial resources for his care.

A patient who is eligible for Medicare has the right to know, upon request and in advance of treatment, whether the health care provider or health care facility accepts the Medicare assignment rate.

A patient has the right to receive, upon request, prior to treatment, a reasonable 
estimate of charges for medical care.

A patient has the right to receive a copy of a reasonably clear and understandable, itemized bill and, upon request, to have the charges explained.

A patient has the right to impartial access to medical treatment or accommodations, regardless of race, national origin, religion, physical handicap, or source of payment.

A patient has the right to treatment for any emergency medical condition that will deteriorate from failure to provide treatment.

A patient has the right to know if medical treatment is for purposes of experimental research and to give his consent or refusal to participate in such experimental research.

A patient has the right to express grievances regarding any violation of his rights, as stated in Florida law, through the grievance procedure of the health care provider or health care facility which served him and to the appropriate state licensing agency.

A patient is responsible for providing to his health care provider, to the best of his knowledge, accurate and complete information about present complaints, past illnesses, hospitalizations, medications, and other matters relating to his health.

A patient is responsible for reporting unexpected changes in his condition to his health care provider. 
A patient is responsible for reporting to his health care provider whether he comprehends a contemplated course of action and what is expected from him. A patient is responsible for following the treatment plan recommended by his health care provider.

A patient is responsible for keeping appointments and, when he is unable to do so for any reason, for notifying the health care provider or health care facility. A patient is responsible for his actions if he refuses treatment or does not follow the health care provider's instructions.

A patient is responsible for assuring that the financial obligations of his health care are fulfilled as promptly as possible.

A patient is responsible for following health care facility rules and regulations affecting patient care and conduct.

Public support for euthanasia has been increasing. A New York Times / CBS News poll found fifty-three percent (53\%) of Americans felt that physicians should be allowed to assist a terminally ill person to die. Three states have undertaken to put laws into effect to legalize active euthanasia. However, two of these attempts have failed. Initiative 119 appeared on the 1991 state ballot in Washington State. This initiative would have legalized active euthanasia under certain circumstances, but it was defeated by a narrow margin of 54 to 46 . The 1994 California Initiative (Proposition 161) also failed. After much debate in 1994 the state of Oregon legalized active voluntary euthanasia. 
The Hemlock Society which was founded in 1980 with 28,000 members supports the option of active voluntary euthanasia for patients with advanced terminal or severe incurable illnesses. Their membership grew to 38,000 in 1991. Humphrey (1991), an active member of the Hemlock Society, wrote a very controversial book called "Final Exit" which details practical step by step information for choosing death by suicide.

The study of death and dying is called thanatology. Thanatology includes the stages of death and dying, different ways of approaching death (intellectually, with humor, etc.), death and children, and grievance. Knott, Ribar, Duson and King (1989) wrote a book with explicit details on death and dying issues. This book even provides the reader with instrumental exercises which include role playing on death issues.

Nurses who work in close contact with patients are likely to be caught in a web of ethical dilemmas concerning euthanasia. The American Nurses Association has developed a Code of Ethics which defines the professional standards of conduct and describes the goals and values of the nursing profession. This Code is a set of ethical principles which should aid nurses in deciding the proper conduct for specific situations.

The underlying principles of these codes include respect for autonomy (self determination), beneficence (doing good), nonmaleficence (avoiding harm), justice (treating patients fairly), veracity, fidelity and confidentiality.

\section{NURSING THEORIES:}

Nursing theories focus mainly on the prevention of illness and promotion of health. Two nursing theorists that would appeal to the humanitarian moral view of 
euthanasia are Abdellah and Watson. In Abdellah's theory she emphasizes holistic nursing care, the nurse assesses the physical, emotional, intellectual, social, and spiritual needs of the client and the family. Abdellah identified four areas in which clients may have unmet needs, these four areas are: 1. comfort, hygiene, and safety, 2. physiological balance, 3. psychological and social factors, and 4. sociological and community factors. From these four areas Abdellah developed 2 lnursing problems which focused on the client's needs. In Abdellah's twenty-one nursing problems (1960), number one states "to maintain good hygiene and physical comfort" (Potter and Perry, 1993). It is consistent with the belief that no one should endure relentless pain (Haddad, 1991). Watson's humanitarian view as evidenced in her Theory of Human Caring, supports the moral justification of euthanasia. In her eleven assumptions related to human care values written in 1985 , Watson stated that "caring is the essence of nursing and the most central and unifying focus for nursing practice." She also assumed that "care and love are the most universal, the most tremendous and the most mysterious of cosmic forces; they comprise the primal and universal psychic energy." Watson also supports self determination. In her philosophical claims, she states that "nonpaternalistic values related to human autonomy and freedom of choice" were an integral part of human care (Fawcett, 1993).

\section{HOSPICE NURSING:}

Hospice nursing is a unique component of the overall nursing field. The philosophy of Hospice nursing is completely different from hospital nursing. Schraff 
(1984) compared hospital to hospice care and was able to identify numerous differences. Some of these differences included the problem, outcome, setting, environment, type of care, caregivers, length of stay, and family involvement. Paradis (1985) identified the philosophy of hospice nursing as having the following aspects of care:

The relief of social, emotional, and physical distress, particularly pain in all its forms.

The value of home care or a homelike environment in which care can be provided.

The potential role of the family members, friends, and volunteers in performing various caregiving functions.

The need to carefully monitor the symptoms and progress of an illness while keeping the patients and family informed.

The need to support, assist, and respect the wishes of families as well as patients. The importance of having health professionals available to help patients and families when needed.

The usefulness of a medically directed team approach in meeting the needs of patients and families.

The value of bereavement follow - up with families after a patient's death.

The importance of providing hospice services to all dying persons regardless of their ability to pay.

Hospice nursing primarily focuses on palliative care. Palliative care concentrates 
on alleviating symptoms and controlling pain. Schraff (1984) identified pain as being physical, social, psychological, and spiritual. Pain control is of primary importance in hospice care. Alleviation will give the patient time and energy to tie up loose ends before they die.

Schraff (1984) also identified hospice care as having four basic principles. First, the patient and the family are one unit of care: meaning both of their needs are of equal importance. Second, an interdisciplinary team provides the total care of the patient and family, these include physical, psychological, social, and spiritual. Third, the patients pain and collateral symptoms associated with the terminal illness will be controlled, but no heroic measures used to save the patient. Fourth, bereavement follow - up is provided to all family members. Hospice nursing arose from a need to remove terminally ill patients from an acute care setting to an environment where there was nourishing, empathetic, and supportive care for the dying patient.

\section{LITERATURE REVIEW:}

Research on nurses' attitudes toward active euthanasia is limited. Anderson and Caddell in their research "Attitudes of Medical Professionals Toward Euthanasia in 1993, sampled sixty-five health care workers. Only forty of the sampled were nurses.

"Voluntary Euthanasia and the Nurse: An Australian survey", presents the attitudes and practices of nurses who were requested to provide active and passive euthanasia for the terminally ill. Seventy-eight per cent (78\%) of the participants thought the law should be changed and the majority supported active voluntary euthanasia. 
Seventy-eight per cent (78\%) of the nurses thought that the law should be changed to allow physicians to take active steps to bring about a patient's death under certain circumstances (suffering, pain, patient's request) and sixty-five per cent $(65 \%)$ of the nurses indicated that they would be willing to collaborate with physicians in the provision of active voluntary euthanasia if it were legal (Kuhse and Singer, 1993).

In the Netherlands, it has been possible to practice voluntary euthanasia quite openly without fear of prosecution, as long as the action is carried out under conditions laid down by the courts and accepted by the medical profession (Rigter, 1989; DeWachter, 1992).

A 1982 survey among health care workers in Japan found that eighty-four per cent $(84 \%)$ of the Japanese people would prefer to die with dignity rather than prolong life with extraordinary means (ventilators, hyperalimentation, etc.) (Takeo, Satoh, Minamisawa \& Mitoh, 1991).

The literature review reveals conflicting and divergent views towards active euthanasia or physician - assisted suicide. Those who support active euthanasia and physician - assisted suicide argue for the ethical principles of respect for autonomy, respect for beneficence and justice (Coyle, 1992, p. 43). Contrarily, those who oppose euthanasia and physician assisted suicide argue for the ethical principles of nonmaleficence and beneficence (Coyle, 1992, p. 43).

The right of a competent person to refuse medical care, including life sustaining treatment has been widely recognized from both ethical and legal viewpoints. Various 
studies have identified variables such as nutrition, ventilators, cardiopulmonary resuscitation or medications as life sustaining treatments that could be withdrawn at the patient's request (Evans, 1990; Grant, 1993; Guarino \& Antoine, 1991; Hogue, 1990; Jansson \& Norberg, 1989; Kuhse \& Singer, 1989; Lee, Swinburne, Fedullo \& Wahl, 1994; Light \& Connelly, 1989; Marsden, 1990; Preston, 1994; Savage, Cullen, Kirchhoff, Pugh \& Foreman, 1987; Solomon et al., 1993). This right has been based on our society's theorem of self determination or autonomy. The right to autonomy says that it is our duty to respect people as individuals, thereby permitting them to make the choices (based on their beliefs, values or life plan) that determine the course of their lives.

Various studies have identified autonomy as a constituent for the supporting of active euthanasia or physician assisted suicide (Battin, 1992; Coyle, 1992; Davis et al., 1993; Davis \& Slater, 1989; Evans, 1990; Kowalski, 1993; Kuhse \& Singer, 1989; Lee et al., 1994; Marsden, 1990; Meyer, 1993; Ringerman \& Koniak - Griffin, 1992; Shapiro, Derse, Gottlieb, Schiedermayer \& Olson, 1994; Solomon et al., 1993; Weir, 1992; Young, Volker, Rieger \& Thorpe, 1993). Autonomy is the ethical theorem from which advance directives (such as living wills and powers of attorney) were derived. However, within the principle of respect for autonomy there has to be an accurate exchange of information about the disease status, treatment, supportive options and planned care. The determination of the patient's understanding and the implications of their decisions must be clearly identified. 
Coyle (1992) identified the principle of respect for beneficence, which implies that euthanasia should be legal because it benefits the individual requesting it, the family and society and because it is a compassionate act. It benefits the individual because they are requesting euthanasia based on their beliefs and values. It benefits the family because they are not required to make end - of - life decisions for a family member, they do not have to endure the prolonged death usually associated with our society, the financial burden and strain is decreased and they know that the patient's wishes were acknowledged. Euthanasia benefits society because it releases resources which can be utilized more effectively and it decreases the financial strain. Several studies distinguished severe suffering as a justification for euthanasia or physician assisted suicide (Davis et al., 1993; Shapiro et al., 1994; Young et al., 1993).

The principle of justice involves the concept of fairness, distribution of goods and service and access to equal care (Coyle, 1992, p. 43). Menzel (1992) recognizes the possibility of rationing due to the escalation of health care costs. Menzel (1992) also explains that our society desires to use the available resources effectively, therefore, there is a need to compare the benefits of alternative care.

The ethical principle of nonmaleficence encompasses the concept that no harm or evil should be inflicted on a person (Coyle, 1992, p. 43). The question of malice contains various points. The physicians' role as healer and curer would change and would include the new role of elimination of human lives, therefore, the trust instilled in physicians today may be altered. There may be a decrease in research in palliative 
care because the bedside care for dying patients may recede. This change may cause patients to be afraid to refuse treatment or go to hospitals because of the possibility of their death being hastened against their will.

There is an unfortunate possibility of abuse related to euthanasia which the opposing advocates, call the "slippery slope". Battin (1992) identified three (3) types of possible abuse associated to active euthanasia or physician assisted suicide. Interpersonal abuse may occur which relates to abuse that occurs within the family for the sake of resentment or greed. A family member may maliciously pressure the patient due to the lack of resources, hostility or greed to choose active euthanasia or physician - assisted suicide. There may also be an unconscious bias towards euthanasia and the family may unintentionally transmit messages favoring euthanasia.

Professional abuse, by physicians, is also a danger. This might include manipulation of the truth by providing inaccurate diagnosis or prognosis or insensitivity in telling the truth. Physicians may use unwanted, unnecessary or inadequate sedation for the treatment of pain. Physicians may refuse to offer alternative treatments which may provide symptom relief. Physicians may recommend or use euthanasia too readily without offering alternative or supportive options first. Ultimately, the worst scenario would be a physician imposing euthanasia to cover up his or her mistakes.

Institutional abuse may consist of altering the actual choices available to the patient depending on the financial means of the patient. Institutional abuse may vary depending on the type of institution: hospital, insurance company, nursing home, or 
government agency. Hospitals may offer less care or barriers may be imposed for certain treatments. Some helpful options may be completely withdrawn. Nursing home care may be replaced with euthanasia to cut costs. Insurance companies may refuse to cover many treatments or all coverage on a patient with a prognosis which is considered futile.

Other reasons for opposing euthanasia or physician assisted suicide include an inadequate understanding of the stages of death and dying and family, staff, or societal bereavement. Lastly, those opposing euthanasia argue that death is irreversible, therefore, it can not be rescinded if an error is made and the patient cannot change their mind after the fact.

Many articles have focused on the issue of euthanasia or physician assisted suicide but few scientifically based studies have been done on the subject. The few studies done on euthanasia have been focused on foreign countries and physicians.

Johnson and Weiler (1990) published an article in the form of a debate on nursing issues and implications of the aid in dying (assisted suicide or euthanasia). Nurses' roles will include participation in educating, supporting and counseling on aid in dying issues. That article identified many important issues and implications that nurses may be faced with if euthanasia were legalized but it was not a research study with statistical analysis or evaluation.

Miller (1992) published an intresting article on hospice care as an alternative to euthanasia which indicated the importance of open communication and adequate pain relief. Miller (1992) cited that "even with an experienced terminal care team $52.5 \%$ of 
the patients suffered such endurable symptoms prior to death that they had to be sedated during the last days of their lives (p. 128)." This article was a descriptive study, but lacked statistical analysis.

Shapiro, et al. (1994) developed a descriptive study on physicians attitudes towards euthanasia. The study was done in the United States, with 740 completed and analyzable surveys returned, making it a $33 \%$ response rate. This study found that physicians felt comfortable performing euthanasia on incompetent, nonterminal patients who had left advanced directives. The majority of physicians did not feel as comfortable with euthanasia when resolutions were needed on patients suffering from grave illnesses, injuries, or early progressive neurologic diseases. In this study it was noted that physician's specialties and religions correlated with their responses. The instrument's reliability and validity, data analysis methods and the design were not mentioned.

Preston (1994) identified the "double effect" which he explicated as being a fallacy of allegedly unintended death due to oversedation for the intention of pain relief. This article indicated that the confounding difference between euthanasia, withdrawal of life support treatments and the double effect is not the "killing" of a patient, but the common acceptance of the latter two medical practices. Preston (1994) indicated that physicians supported euthanasia but were not willing to be a participant. However, $70 \%$ of the physician stated they would like euthanasia to be an option if they were a patient. This article basically identified the different types of euthanasia and the physician's role. This was not a scientifically based study, it did not contain any statistical analysis. 
Baume and O'Malley (1994) performed a study on physicians' attitudes towards euthanasia and physician assisted suicide in New South Wales and the Australian Capital Territory. This was a survey sent to a random sample of 2000 physicians with a $76.1 \%$ response rate. The questionnaire was the same questionnaire used in 1987 by Kuhse and Singer but with some revisions for clarity. Statistical analysis was done using methods from Armitage and Berry's (1987) on medical research. The design was not stated. The findings showed that half of the physicians who were surveyed had been approached to perform euthanasia and $28 \%$ had complied. Euthanasia was still illegal in these countries when this study was in progress, but there seems to be a general acceptance by physicians and the general community (Morgan Gallup polls $75 \%$ in $1987,77 \%$ in 1990 , $78 \%$ in 1993 ). This illegality has not prevented the substantial number of physicians from practicing euthanasia. Eighty - nine per cent $(89 \%)$ of the physicians who admitted to practicing euthanasia, had performed euthanasia more than once and nearly all of the physicians felt they had done the right thing. This study found that there were higher levels of support for euthanasia and physician assisted suicide in New South Wales and suggested revisions of the current laws.

Takeo, Satoh, Minamisawa and Mitoh (1991) executed a study on health care workers' (physicians and nurses) attitudes on euthanasia in Japan. In this study, a questionnaire designed for health care workers was developed, the means of protecting the participants was not identified. The sample included 72 physicians, 202 nurses and 68 student nurses. The study found that more physicians (50\%) approved of euthanasia 
than nurses $(26 \%)$ for a patient in a vegetative state. Only a small percentage $(14 \%)$ disapproved of euthanasia. All of the health care workers seemed to have preferred euthanasia if they were the patient in the vegetative state (physicians $76 \%$, nurses $70 \%$, student nurses $68 \%$ ). A comparison study was done with similar results, allowing for reliability. Validity and the study's design were not identified. A 1982 survey that was cited identified that $84 \%$ of the Japanese people would prefer to die with dignity than prolong life with artificial means such as ventilators, feeding through tubes, medications to maintain blood pressure (inatropes), etc.

Cohen, Fihn, Boyko, Jonsen, and Wood (1994) performed a study on Washington State's physicians' attitudes on euthanasia and physician assisted suicide. Random sampling was used to send 1355 questionnaires with a $69 \%$ response rate. The statistical analysis was thoroughly computed with a $95 \%$ confidence interval. Logistic regression was used to assess independent variables. Validity was acknowledged and enhanced by using unbiased terminology in the questionnaire. This study found that $48 \%$ of the respondents felt euthanasia is never justifiable and $42 \%$ disagreed. Forty - four per cent $(44 \%)$ of the respondents felt euthanasia should be legal in some situations, but only $33 \%$ stated they would be willing to participate.

Davis and Slater (1989) initiated a study comparing nurses from Australia and the United States on their attitudes and beliefs on euthanasia. A convenience sample of 30 Americans and 32 Australians responded to a survey with eight vignettes. This study found there was a failure in agreement between the Australian and American nurses. The 
disagreement concentrated on the differences in the health care systems. This study had a small sample size, poor statistical analysis and no instrument reliability or validity was mentioned.

Davis, et al. (1993) performed a study on euthanasia and nurses' attitudes in seven countries. The countries involved in the study were Australia, Canada, People's Republic of China, Finland, Israel, Sweden and the U.S. A convenience sample of 319 nurses were interviewed using a structured interview guide. A content analysis was performed to identify themes of similarities and differences among the seven groups of nurses. The instruments' reliability and validity, design, and means of protection for participation were not mentioned. This study found that the majority of nurses did not ethically justify euthanasia and for those who did, they did so only if the patient was suffering.

The only study found on American nurses' attitudes on euthanasia or physician assisted suicide was by Young, Volker, Reiger and Thorpe (1993). This study focused specifically on oncology nurses. Random sampling was used and questionnaires were sent to 2000 members of the Oncology Nursing Society, with a response rate of $61 \%$. Two ethicists and an oncology nurse specialist established content validity. The study found that overall, oncology nurses had divergent views on euthanasia and physician assisted suicide. Although many nurses favored euthanasia and physician assisted suicide, most were reluctant to participate in the act itself. These results are comparable with the previous studies done with physicians. The difference was that although some 
nurses did not agree with euthanasia or physician assisted suicide, they were willing to set their personal beliefs aside and support the patients who requested it. The most intriguing finding was that many of the nurses in this study indicated that having a prior relationship with the patient was an important determinant in their decision to participate in euthanasia or physician assisted suicide.

\section{THEORETICAL FRAMEWORK}

Dworkin (1988) identified the theory and principles of autonomy and difference of autonomy as compared to other theories. Autonomy has functions that are within moral, political and social notions. Within all three cases there are values derived as to how things are considered through the reasons, values, and desires of the individual person and how these principles are shaped and formed (See Table I) .

"In the political concept, autonomy is used as a basis to argue against the design and functioning of political institutions that attempt to impose a set of ends, values, and attitudes upon the citizen of a society" (Dworkin, 1988). This infringement may be based on the utilitarian view which envisions what is good for society. Those favoring autonomy argue that each individual citizen must accept the rules before they are imposed on one's morals. Autonomy is referred to as the notion of equal respect. Furthermore, a government is required to treat all of it's citizen neutrally, meaning it cannot have biases of some interests over others.

Within the moral case the main argument is that individuals desire choice, free will and the ability to accept their own moral code. Everyone knows that all individuals 
have a history. Humans develop socially and psychologically in a given environment with a set of biological endowments. How each individual dictates the order of their moral values has to do with autonomy.

There are entities that impose on the autonomous character of individuals. "Both coercion and deception infringe upon voluntary character of the agent's actions" (Dworkin, 1988). If this occurs the individual will feel used and will see themselves as an instrument of another's will.

There are certain characteristics and concepts which autonomy embraces. Dworkin (1988), explains these concepts as being liberty, desires and authenticity. In order for autonomy to exist all three concepts must be included.

Liberty is the ability of a person to do what he wants, to have options that are not closed or made less eligible by actions of other agents. Although liberty is a concept in itself, there must be some degree of liberty within the concept of autonomy. A person has to have the liberty to decide what is right for them.

Desires is defined as to wish and long for, to want or crave. We focus upon desires in considering the willfulness of our actions. Desires gives us the ability to reflect upon and adopt attitudes toward our passions, wishes and intentions.

Authenticity means to be worthy of trust, reliance, or belief; to be genuine or real. Authenticity is a necessary condition for being autonomous. A person's first and second order of desires are genuinely their own. The first order of desires is what comes immediately to mind. If this desire is unacceptable ( due to moral, social or legal 
convictions) the second order of desires is formed.

Autonomy has been identified as a global concept. It is seen everywhere in the world as an integral characteristic of people. Dworkin (1988) identifies four constituents and qualities of autonomy, these are listed as follows.

1. It is a feature that evaluates a whole way of living one's life and can only be assessed over extended portions of a person's life whereas identification is something that may be pinpointed over a short period of time.

2. Identification does not seem to be what is put in question by obvious interference with autonomy. The person who is ignorant or manipulated in various ways is not having his identifications interfered with, but rather his capacity or ability either to make or reject such identifications.

3. There seems to be an implication of the position that is counterintuitive. A person does this by either changing their motivation or by changing their higher order of preferences.

4. There is a link between the idea of autonomy and the ability to make certain desires effective in our actions. Autonomy should have some relationship to the ability of individuals, not only to scrutinize critically their first order of motivations (desires) but also to change them if they so desire. A person who can not affect his desires to act justly or compassionately is thought by that fact alone to be nonautonomous (See Table II) .

Autonomy is a concept that allows individuals choices. If an individual notices a 
quality or notion that stimulates them, they may alter their preferences and incorporate then into their own morals and values. To make them effective as one's own morals and values. "Power, liberty, and control over important aspects of one's life are not the same as autonomy, but are necessary conditions for individuals to develop their own aims and interests and to make their values effective in the living of their lives" (Dworkin, 1988).

Within his book, Dworkin (1988) described moral philosophy and more specifically moral autonomy. He described the morally autonomous person as someone whose principles are their own. He also gave the following characteristics of what it might mean for moral principles to be one's own.

1. A person is morally autonomous if and only if he is the author of his moral principles, their originator.

2. A person is morally autonomous if and only if he chooses his moral principles. (An autonomous person can not accept the judgement of others. He may rely or accept the judgement only after independent reasoning and weighing the evidential value of the judgement.)

3. A person in morally autonomous if and only if the ultimate authority or source of his moral principles is his will.

4. A person is morally autonomous if and only if he decides which moral principles to accept as binding upon him.

5. A person is morally autonomous if and only if he bears the responsibility for 
the moral theory he accepts and the principles he applies.

6. A person is morally autonomous if and only if he refuses to accept others as moral authorities, that is, he does not accept without independent consideration the judgement of others as to what is morally correct.

Autonomy is a concept that constitutes what it is to be an individual. It allows us to make our life ours. It allows us to respect other individuals as persons, as independent centers of consciousness, allowing them to make whatever choices coincide with their values and preferences. To be an autonomous person, one must be able to critically reflect upon issues and then attempt to accept or change his or her preferences, desires, values and ideas. Being autonomous gives one the ability to define and value the world as they see it and then allows them to decide how they should act (See Table III) .

\section{RESEARCH QUESTIONS}

This descriptive study is designed to answer the following research questions:

1. What are the attitudes of hospice nurses towards active voluntary euthanasia or physician assisted suicide?

2. To what extent are hospice nurses willing to participate in active voluntary euthanasia or physician assisted suicide?

3. Are there any relationships between hospice nurses demographic characteristics and their attitudes towards active voluntary euthanasia? 
Table I Schematic on the nurses autonomy with issues on euthanasia

\section{Patient (Pt.)}

Pt. wants everything done till death occurs.

Nurses role defined by ANA and easily understood.
Pt. wants to have physician assisted suicide / dying or active voluntary euthanasia.

Euthanasia is not legal in the United States. The nurses role defined by ANA does not support euthanasia but specifically states the nurse is to be the advocate of the Pt.

Nurse in dilemma with role as defined by ANA.

Nurse develops own moral principles towards euthanasia.

Conclusion: Future changes in the law. Future changes in ANA code for nurses. 
Table II Schematic of nurses autonomous (professional) decision on euthanasia if it were legal

Competent patient with a terminal illness wants to have physician assisted suicide / dying or active voluntary euthanasia

\section{Assuming active voluntary euthanasia is legal and the ANA supports the nurses decision}

Nurses autonomous decision must consist of the following:

\section{Professional}

1. The nurse evaluates the patient's life over an extended time.

2. The nurse identifies if this is an autonomous decision by the patient. That the patient has not been coerced or manipulated in any way.

3. The nurse discusses with the patient all alternative treatment and death and dying issues and euthanasia. The family is included in the discussion but is not allowed to coerce the patient or make the decision for the patient.

4. The nurse determines that the patient's decision is genuine and an autonomous decision. 
Table III Schematic of nurses autonomous (personal) decision on euthanasia as if it were legal

First the nurse must act in her professional role and determine if the patient's decision is truly autonomous. Second the nurse must assess her own autonomous decisions on euthanasia, on whether to support the patient with their decision, whether to stay with the patient throughout the procedure and whether to assist or perform the actual procedure.

Personal

1. The nurse assesses her own moral principles.

2. The nurse determines if her own moral principles accept or reject the patient's decision for euthanasia.

3. The nurse decides whether it is within her morals to support the patient with their decision and stay with the patient throughout the procedure.

4. The nurse decides whether it is within her morals to assist or perform the procedure.

5. The nurse adjusts her morals according to her own judgement. She is not coerced or manipulated in any way about euthanasia or this particular situation.

6. The nurse accepts her moral decisions making them her own. The nurse makes her autonomous judgement and takes full responsibility for her decision. 


\section{CHAPTER III:}

METHODOLOGY

\section{APPROACH AND DESIGN}

A descriptive correlational survey was be used in this study. Data was collected utilizing a self report paper and pencil questionnaire. The nursing staff from six hospice centers were surveyed for their attitudes on voluntary active euthanasia or physician assisted suicide / dying. The demographics of age, religion, and education was analyzed in this study to determine any significance.

\section{SAMPLE AND SAMPLING METHOD}

The target population were hospice nurses of South Florida. The assessable population was the hospice nurses from six local hospice centers in South Florida. All six of the hospice centers were private - nonprofit organizations. A convenience sample of registered nurses were recruited from the six hospice centers.

To be eligible for participation in the study, the subjects must: 1 . be registered nurses, 2. have at least six months experience in hospice nursing and 3. be or have been employed by a hospice center.

\section{INSTRUMENT}

Data was collected using the Nurse's Attitudes Regarding Physician Assisted Dying (NARPAD) questionnaire (see Appendix I). This questionnaire consist of four vignettes, demographic data and an awareness and opinion section. The four vignettes 
consist of situations containing nursing exercises and their beliefs on physician assisted dying. The nurses were asked to select one of the four possible responses that best reflects the decision the nurse would make in that position. The vignettes were designed by Young (1993) to assess the importance of nursing relationships with patients having physician - assisted dying, the willingness of the nurses to actually administer the medication which causes death, the impact of pain and suffering on beliefs about the relevance of physician - assisted dying.

The subjects were asked to answer the questions as if physician - assisted dying were legal. At the end of the questionnaire there were questions to determine the nurses awareness of organizations involved with death issues and legislation that would legalize physician - assisted dying. The nurses position on physician assisted dying was also explored.

With the permission of Young (1993) the questionnaire will be utilized. (Young developed the questionnaire and utilized it in the research of oncology nurses attitudes towards voluntary physician - assisted dying), The content validity of this questionnaire was established for the previous study by a panel of two ethicists and an oncology nurse specialist, all of whom had experience with issues related to death and dying. A pilot study of 76 oncology nurses was conducted to assess instrument readability and clarity. Modifications of the tool were made after the pilot study. The study result are as follow: Vignette 1: $44 \%$ of nurses agreed with the notion of physician assisted dying and would stay in the room with the patient while receiving the medication; Vignette $2: 37 \%$ of 
nurses agreed with physician assisted dying and would stay with the patient even if they had no prior relationship; Vignette 3: $34 \%$ of the nurses indicated they agreed with physician assisted dying but would not administer the medication; Vignette $4: 48 \%$ of nurses agreed with physician assisted dying and would stay with the suffering patient while receiving the medication. Reliability of this study was established after the studies were compared.

\section{DATA COLLECTION PROCEDURES}

Prior to data collection, approval of the research protocol was secured from the Florida International University Research Council (Appendix 1) Upon approval, nurses were notified at all five hospice centers of the study by either announcement in the nurses lounge and conference rooms or by a designee of the hospice center.

The questionnaire contains some demographic questions, four vignettes describing patient care situations and possible responses based on beliefs about physician - assisted dying and a few questions that explore awareness of organizations and legislation that promote the legalization of active voluntary euthanasia. The hospice nurses age, religion, and education were collected and interpreted with the result and determine any significant correlations with the findings.

The subjects were briefly interviewed to determine their qualifications for the study. All subjects who met the screening criteria were concisely introduced to the study and its importance, to the informed consent and to the questionnaire.

The participants were instructed of the informed consent which discuses the 
purpose of the study, potential benefits of the study, basic information on the questionnaire and the participants responsibilities. Along with the informed consent all of the participants were counseled on the importance of completing the questionnaire anonymously and not discussing the study or subject matter with any other nurses until the study had been completed in order to prevent biases.

Hospice nursing is a subgroup of nursing, therefore, this study analyzed subgroup effects. No manipulation was needed because the questionnaire is specific and was written with simple terminology.

The nurses were informed of the study by either reading the flyers posted throughout the hospice center or by a designee at each hospice center. The flyer and designee informed the nurses of the study at hand, the dates in which the principal investigator would be screening potential participants and handing the questionnaires out to the eligible subjects and the principal investigator's phone number. The principal investigator's phone numbers was provided in case some of the subjects who would have liked to participate were unable to attend the meeting dates.

The questionnaires were handed to the nurses after meeting the screening criteria. The principal investigator provided a brief introduction, an explanation of the study, purpose of the informed consent, benefits and risks involved in the study and the importance of keeping the study anonymous was discussed with all potential participants. The questionnaires were numbered with different sequences for the six hospice centers to properly identify participation. 
The nurses only needed a pencil or pen to complete the questionnaire. The questionnaire took a maximum of ten minutes to complete. After the questionnaires were completed the nurse either dropped the questionnaire into a sealed box at a designated area or mailed them in the addressed and stamped envelopes provided. The box was emptied and the questionnaires were collected three times a week by the principal investigator.

\section{PROTECTION OF PARTICIPANTS}

The rights and responsibilities of the participants were protected by having the participants sign an informed consent form. All participants were screened and counseled on the study, potential benefits, basic information about the questionnaire and the significance of keeping the study anonymous and not discussing with their peers. All surveys were anonymous. The informed consent included the rights and responsibilities of the participants, a brief explanation of the purpose of the study, information about the questionnaire and it being anonymous, the study's potential benefits, and minimal risks. If the nurses did not want to sign their name on the questionnaire they could sign only their initials to prevent identification of participant or leave blank. The nurses dropped their questionnaires into a sealed box or mailed them in the addressed and stamped envelopes provided.

\section{DATA ANALYSIS}

In preparation for the computerized data analysis, the raw data was compiled in a master table, organized accordingly to demographics and the main study variables. A 
quantitative statistical analysis was used to determine any significance. Frequencies and percentages were calculated on each of the questionnaire responses. Means were calculated for demographic data of age, education, and religion. The demographic data was presented in graphs with percentages identified. Chi square test was utilized to provide continuity with Young's study (1993) and to determine the relationships between the vignette responses and selected demographic characteristics. 


\section{CHAPTER IV:}

PRESENTATION AND ANALYSIS OF DATA

\section{CHARACTERISTICS OF THE SAMPLE}

The sample consisted of 100 hospice nurses from six hospice centers in South Florida. Three hundred questionnaires were distributed; 100 responded with usable questionnaires, for a response rate of $33 \%$. Numerous personal contacts with directors of education, nurse managers, supervisors and nursing staff were made to maximize the return rate. The poor response rate was attributed to the controversial subject matter on hand and the participants lack of understanding and exposure to research.

The frequency and percentage distribution of the respondents by demographic factors are presented in Table 4. As depicted in Table 4, the sample was predominantly female $(98 \%)$, ranging in age from twenty - one to seventy - three with a mean age of 45.7 years. Most of the nurses graduated from baccalaureate nursing programs (40\%). Thirty - two per cent graduated from an associate degree program, 19\% from a diploma program and $9 \%$ from a master's program. The majority $(37.6 \%)$ of nurses were Roman Catholic and (34.7\%) Protestant, 3\% were Agnostic, 3\% were Jewish, $2 \%$ were Atheist. Various religions such as Christian and Methodist were classified as "other" which comprised of the $19.8 \%$ sample. Due to the small sample sizes, the Agnostic, Jewish and Atheist religions were combined into the "other" category in order to perform an adequate chi square analysis. 
The nurses age, education and religion were analyzed using a chi square analysis.

To determine the relationship between the demographic characteristics and the vignette responses,

Table 4: Frequency and Percentage Distribution of Respondents by Gender, Age, Education and Religion

DEMOGRAPHIC VARIABLE FREQUENCY

PERCENT

Gender

Female

Age

21 - 40 years

$41-49$ years

$50+$ years

Education

Diploma

Associate Degree

Baccalaureate Degree

Master's Degree
19

32

40

9
19.0

32.0

40.0

9.0

Religion

Agnostic

Jewish

Roman Catholic

Atheist

Protestant

Other
3

3

38

2

35

20
3.0

3.0

37.6

2.0

34.7

19.8 
each variable was analyzed separately. The nurses were asked to assume that physician assisted dying was legal for a competent, terminally ill patient who requested such assistance.

\section{RESEARCH QUESTION 1}

What are the attitudes of hospice nurses towards active voluntary euthanasia or physician - assisted suicide?

The findings related to this question are presented in Table 5 which depicts the average responses of the nurses to vignettes 1 through 4 . Furthermore, Table 6 represents the nurses average responses to legalization of active voluntary euthanasia. These results indicate that a small per cent of the nurses did not agree with active voluntary euthanasia. However, when the element of pain and suffering (Sit 4) was added a small per cent of nurses did believe that this was a respectable justification for active voluntary euthanasia. Overall, with legislation on euthanasia a small per cent of nurses agreed with legalization (Table 5). These findings are comparative to the previous studies reviewed. 
Table 5: Average responses of the nurses to vignettes 1 through 4

Sit $1=$ Nurse has cared for patient 2 years, Pt.. wants AVE and wants nurse to stay as bedside

Sit 2 = Nurse has never met patient, Pt.. wants AVE and wants nurse to stay at bedside Sit 3 = Physician orders medication for AVE, patient wants nurse to administer medication

Sit 4 = Patient has expressed profound suffering numerous times to nurses and request AVE

\begin{tabular}{|c|c|c|c|c|c|}
\hline \multicolumn{2}{|c|}{ Responses } & Sit 1 & Sit 2 & Sit 3 & Sit 4 \\
\hline \multirow{2}{*}{ Agree } & $\mathrm{F}$ & 43 & 43 & 47 & 54 \\
\hline & $\%$ & 42.5 & 42.6 & 46.5 & 55.7 \\
\hline \multirow[t]{3}{*}{ Disagree } & $\mathrm{F}$ & 58 & 58 & 54 & 43 \\
\hline & $\%$ & 57.4 & 57.4 & 53.4 & 44.3 \\
\hline & $\mathrm{n}$ & 100.0 & 100.0 & 100.0 & 100.0 \\
\hline
\end{tabular}

Table 6: Nurses responses on legalization of euthanasia

\begin{tabular}{lll}
\multicolumn{3}{l}{ Legalization vote } \\
\multicolumn{2}{l}{} & \\
YES & F & 54 \\
& $\%$ & 53.5 \\
NO & F & 47 \\
& $\%$ & 46.5
\end{tabular}




\section{RESEARCH QUESTION 2}

To what extent are hospice nurses willing to participate in active voluntary euthanasia or physician - assisted suicide?

The findings related to this question are presented in Table 7 , situation 3 which indicated that $17.0 \%$ of the nurses would administer the medication that would cause death and $83.0 \%$ of the nurses would not. These findings correlated with previous studies, which indicated that whether they agreed with euthanasia or not, the respondent were not willing to administer the medication which causes death.

Table 7: Nurses responses to vignette 3

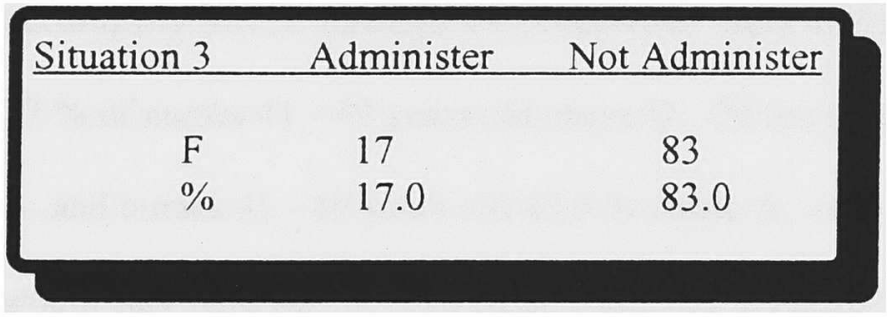

\section{RESEARCH QUESTION 3}

To determine the relationship between hospice nurses demographic characteristics (age, religion and education) and their attitudes towards active voluntary euthanasia or physician - assisted suicide / dying.

The responses to this question are represented in Tables 8 through 24 . There were significant differences noted with the nurses age and situations 1 and 4, also with legalization and adequate pain relief. There were significant values established within the nurses religion and situations 3 and 4 . There were also significant values found with 
the nurses educational level and situation 3.

\section{RELATIONSHIP BETWEEN AGE AND NURSES RESPONSES}

The four vignettes with the nurses responses and their ages are presented in

Tables 8, 9, 10 and 11. Situation \#1 (Table 8) concerns a patient with terminal cancer. This patient has had a relationship for the past 2 years with a nurse, has requested physician assisted dying and would like the nurse to stay in the room with him through the procedure. There were different distributions of answers across the three ages, with a significant value of $p=0.025$. Sixty - three point six per cent $(63.6 \%)$ of the nurses 50 + years of age chose $\mathrm{D}$, which stated they do not agree with PAD and would not accompany Mr. A. through the procedure. Only $25 \%$ of nurses $21-40$ years old and $27 \%$ of nurses $41-49$ years old chose D. Of the nurses $21-40$ years old $42.9 \%$ chose A and nurses $41-49$ years old $45.9 \%$ chose A, which stated they agree with PAD and would stay with $\mathrm{Mr}$. A. Chi square analysis revealed a significant relationship between age and nurses responses to vignette $1\left(X^{2}=14.11, \mathrm{df}=4, \mathrm{p}=0.007\right)$.

In situation 2 (Table 9), the nurse has never met Mrs. C. who is a terminally ill patient. Mrs. C. has requested PAD and would like the nurse to stay with her throughout the procedure. Chi square analysis revealed no significance with the nurses responses with all four answers and no significance was noted after answers $B$ and $C$ were collapsed $\left(X^{2}=5.15, \mathrm{df}=2, \mathrm{p}=0.076\right)$. 
Table 8: Relationships between age and nurses responses to vignette 1

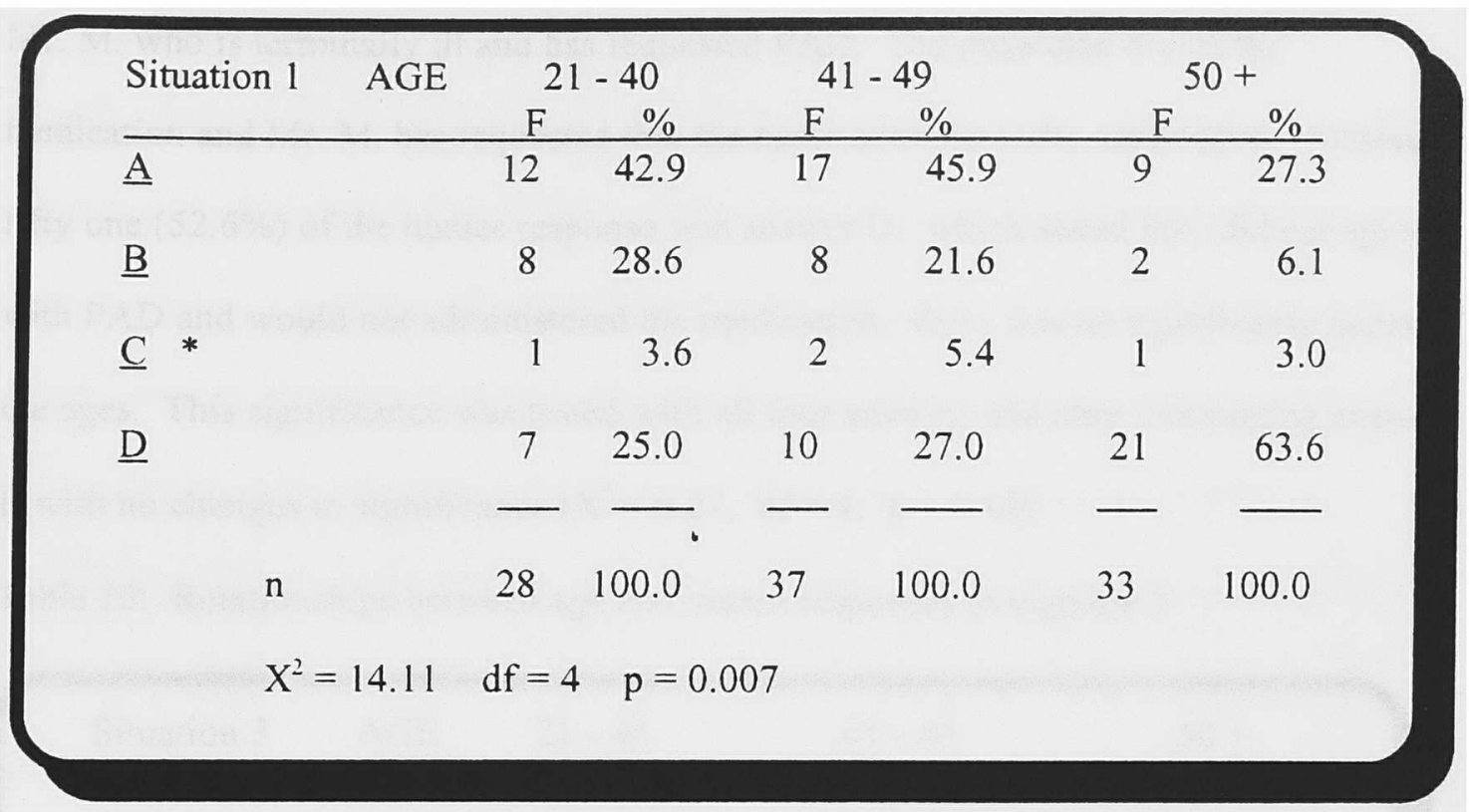

* responses for $\mathrm{C}(\mathrm{N}=5)$ not included in chi square analysis

Table 9: Relationships between age and nurses responses to vignette 2

\begin{tabular}{|c|c|c|c|c|c|c|c|}
\hline \multirow{2}{*}{ Situation 2} & \multirow{2}{*}{ AGE } & \multicolumn{2}{|c|}{$21-40$} & \multicolumn{2}{|c|}{$41-49$} & \multicolumn{2}{|c|}{$50+$} \\
\hline & & $\mathrm{F}$ & $\%$ & $\mathrm{~F}$ & $\%$ & $\mathrm{~F}$ & $\%$ \\
\hline$\underline{A}$ & & 12 & 42.9 & 12 & 32.4 & 8 & 24.2 \\
\hline$\underline{B}^{*}$ & & 6 & 21.4 & 3 & 8.1 & 2 & 6.1 \\
\hline$\underline{C}^{*}$ & & 2 & 7.1 & 6 & 16.2 & 2 & 6.1 \\
\hline \multirow[t]{3}{*}{$\underline{D}$} & & 8 & 28.6 & 16 & 43.2 & 21 & 63.6 \\
\hline & $\mathrm{n}$ & 28 & $\overline{100.0}$ & 37 & $\overline{100.0}$ & $\overline{33}$ & $\overline{100.0}$ \\
\hline & $=5.15$ & $\mathrm{df}=2$ & $p=0.0$ & & & & \\
\hline
\end{tabular}

* responses $\mathrm{B}(\mathrm{N}=11)$ and $\mathrm{C}(\mathrm{N}=10)$ were not included in chi square analysis 
Situation 3 (Table 10) put the nurses in an awkward position, here the nurse met Mr. M. who is terminally ill and has requested PAD. The physician orders the medication and Mr. M. has requested that the nurse administer the medication. Although fifty one $(52.6 \%)$ of the nurses response was answer D, which stated they did not agree with $\mathrm{PAD}$ and would not administered the medication, there was no significance across the ages. This significance was tested with all four answers and after eliminating answer B with no changes in significance $\left(X^{2}=6.27, d f=4, p=0.18\right)$.

Table 10: Relationships between age and nurses responses to vignette 3

\begin{tabular}{|c|c|c|c|c|c|c|c|}
\hline \multirow[t]{2}{*}{ Situation 3} & \multirow[t]{2}{*}{ AGE } & \multicolumn{2}{|c|}{$21-40$} & \multicolumn{2}{|c|}{$41-49$} & \multicolumn{2}{|c|}{$50+$} \\
\hline & & $\mathrm{F}$ & $\%$ & $\mathrm{~F}$ & $\%$ & $\mathrm{~F}$ & $\%$ \\
\hline$\underline{\mathrm{A}}$ & & 6 & 21.4 & 6 & 16.2 & 4 & 12.1 \\
\hline$\underline{\mathrm{B}}^{*}$ & & 0 & 0.0 & 1 & 2.7 & 0 & 0.0 \\
\hline$\underline{\mathrm{C}}$ & & 10 & 35.7 & 14 & 37.8 & 6 & 18.2 \\
\hline$\underline{D}$ & & 12 & 42.9 & 16 & 43.2 & 23 & 69.7 \\
\hline . & $\mathrm{n}$ & 28 & 100.0 & 37 & 100.0 & 33 & 100.0 \\
\hline & $=6.27$ & $\mathrm{df}=$ & $p=$ & & & & \\
\hline
\end{tabular}

* response $\mathrm{B}(\mathrm{N}=1)$ was not included in chi square analysis

In situation 4 (Table 11) the element of pain and suffering was added. Here Mrs. W. also terminally ill and competent has requested PAD. She expresses to the nurse the she " has suffered too much and too long" and requests the nurse to be present for 
administration of medication. With all four answers analyzed there was no significance but after answers $\mathrm{C}$ and $\mathrm{B}$ were collapsed for more accurate testing there was a significant value of $p=0.003$ noted. The older nurses $50+$, chose D more often, which stated that profound suffering is not a sufficient justification for terminating a life and they would not cooperate with Mrs. W's request. Nurses 41 - 49 years old were in the middle with $58.6 \%$ believed profound suffering was sufficient justification and $41.4 \%$ believed it was not. The younger nurses 21 - 40 believed suffering was sufficient justification $78.9 \%$, while only $21.1 \%$ believed it was not justified. Chi square analysis revealed a significant relationship between age and nurses response to vignette 4 ( $X^{2}=$ $11.86, \mathrm{df}=2, \mathrm{p}=0.003)$

Table 11: Relationship between ages and nurses responses to vignette 4

\begin{tabular}{|c|c|c|c|c|c|c|c|}
\hline \multirow{2}{*}{\multicolumn{2}{|c|}{ Situation 4}} & \multicolumn{2}{|c|}{$21-40$} & \multicolumn{2}{|c|}{$41-49$} & \multicolumn{2}{|c|}{$50+$} \\
\hline & & $\mathrm{F}$ & $\%$ & $\mathrm{~F}$ & $\%$ & $\mathrm{~F}$ & $\%$ \\
\hline$\underline{\mathrm{A}}$ & & 15 & 60.0 & 17 & 47.2 & 9 & 27.3 \\
\hline$\underline{\mathrm{B}}^{*}$ & & 3 & 12.0 & 1 & 2.8 & 0 & 0.0 \\
\hline$\underline{\mathrm{C}}^{*}$ & & 3 & 12.0 & 6 & 16.7 & 3 & 9.1 \\
\hline$\underline{D}$ & & 4 & 16.0 & 12 & 33.3 & 21 & 63.6 \\
\hline$X^{2}=$ & & $\begin{array}{c}25 \\
\text { If }=2\end{array}$ & $\begin{array}{l}100.0 \\
p=0.003\end{array}$ & 36 & 100.0 & 33 & 100.0 \\
\hline
\end{tabular}

* responses $\mathrm{B}(\mathrm{N}=4)$ and $\mathrm{C}(\mathrm{N}=12)$ were not included in chi square analysis

The nurses were asked if they would vote in favor of legalization of PAD for the 
competent, terminally ill adults. The answers are depicted in Table 12 with relation to ages. With chi square analysis there were significant relationship between age and nurses responses $\left(X^{2}=9.56, \mathrm{df}=2, \mathrm{p}=0.008\right)$. The older nurses $50+$ chose no $66.7 \%$, while $70.3 \%$ of the nurses $41-49$ years old chose yes and nurses $21-40$ years old were in the middle with $53.6 \%$ voting yes and $46.4 \%$ voting no.

Table 12: Relationship of age and response to legalization of PAD

\begin{tabular}{|c|c|c|c|c|c|c|}
\hline \multicolumn{3}{|c|}{ Legalizing euthanasia $21-40$} & \multicolumn{2}{|c|}{$\cdot 41-49$} & \multicolumn{2}{|c|}{$50+$} \\
\hline response: & $\mathrm{F}$ & $\%$ & $\mathrm{~F}$ & $\%$ & $\mathrm{~F}$ & $\%$ \\
\hline YES & 15 & 53.6 & 26 & 70.3 & 11 & 33.3 \\
\hline NO & 13 & 46.4 & 11 & 29.7 & 22 & 66.7 \\
\hline & 28 & 100.0 & 37 & $\overline{100.0}$ & 33 & 100.0 \\
\hline$X^{2}=9.56$ & $\mathrm{~d} f=2$ & $\mathrm{p}=$ & & & & \\
\hline
\end{tabular}

Table 13 represents the nurses' responses on adequate pain relief. The nurses were asked to rate the pain relief of the patients they have cared for. Answer 4 being the patient had pain relief most of the time and 1 being almost never any pain relief. In condition to the minimal responses to answers 1 and 2, they were analyzed together as one to acquire adequate results. Chi square analysis revealed significant findings $\left(X^{2}=\right.$ $11.35, \mathrm{df}=4, \mathrm{p}=0.023)$. Fifty - three point one per cent $(53.1 \%)$ of the older nurses 50 + and $75 \%$ of the nurses $21-40$ years old believed that their patients had pain relief most of the time. The answers of the nurses $41-49$ years old were distributed more equally. A one way ANOVA (Table 14) was done on all three ages differences on pain 
relief. A mean of 3.71 being answer 4 was noted with a significant value of 0.008 .

Nurses 21 - 40 years old chose a higher pain relief score $(m=3.61)$ for the average than nurses $41-49(\mathrm{~m}=2.95)$ and $50+(\mathrm{m}=3.38)$.

Table 13: Relationship between age and nurses responses to adequate pain relief

\begin{tabular}{|c|c|c|c|c|c|c|}
\hline $\begin{array}{l}\text { Adequate physical } \\
\text { pain relief }\end{array}$ & & -40 & & -49 & & $0+$ \\
\hline response: & $\mathrm{F}$ & $\%$ & $\mathrm{~F}$ & $\%$ & F & $\%$ \\
\hline 1, almost never & 1 & 3.6 & 3 & 8.1 & 0 & 0.0 \\
\hline 2 & 2 & 7.1 & 9 & 24.3 & 5 & 15.6 \\
\hline 3 & 4 & 14.3 & 12 & 32.4 & 10 & 31.3 \\
\hline 4 , most of time & 21 & 75.0 & 13 & 35.1 & 17 & 53.1 \\
\hline $\mathrm{n}$ & 28 & 100.0 & 37 & 10 & 32 & 100.0 \\
\hline
\end{tabular}

Table 14: Analysis of variance of age and mean pain relief

\begin{tabular}{llll} 
ANOVA & $21-40$ & $41-49$ & $50+$ \\
\hline $\begin{array}{l}\text { X Pain relief } \\
\quad \text { Mean }\end{array}$ & 3.61 & 2.95 & 3.38 \\
$\mathrm{~F}=5.12$ & & & \\
$\mathrm{P}=0.008$ & & &
\end{tabular}




\section{RELATIONSHIP BETWEEN RELIGION AND NURSES RESPONSES}

Ensuing, the nurses religion was analyzed to determine if there was any significance in their responses to vignettes $1,2,3$, and 4 , legalization and pain relief. There were six religions the nurses could choose: Agnostic, Jewish, Roman Catholic, Atheist, Protestant and other. The religions Agnostic, Jewish and Atheist were combined with the "other" category because of the ineffectual representation.

Table 15 represents the nurses religions and their responses to vignette 1 . Answer $\mathrm{C}(\mathrm{N}=4)$ was collapsed because of the minimal responses. The vignette was analyzed with all four responses and with three responses and no significant value was noted $\left(\mathrm{X}^{2}=\right.$ 4.57, $\mathrm{df}=4, \mathrm{p}=0.34)$.

Table 15: Relationship of nurses religion and responses to vignette 1

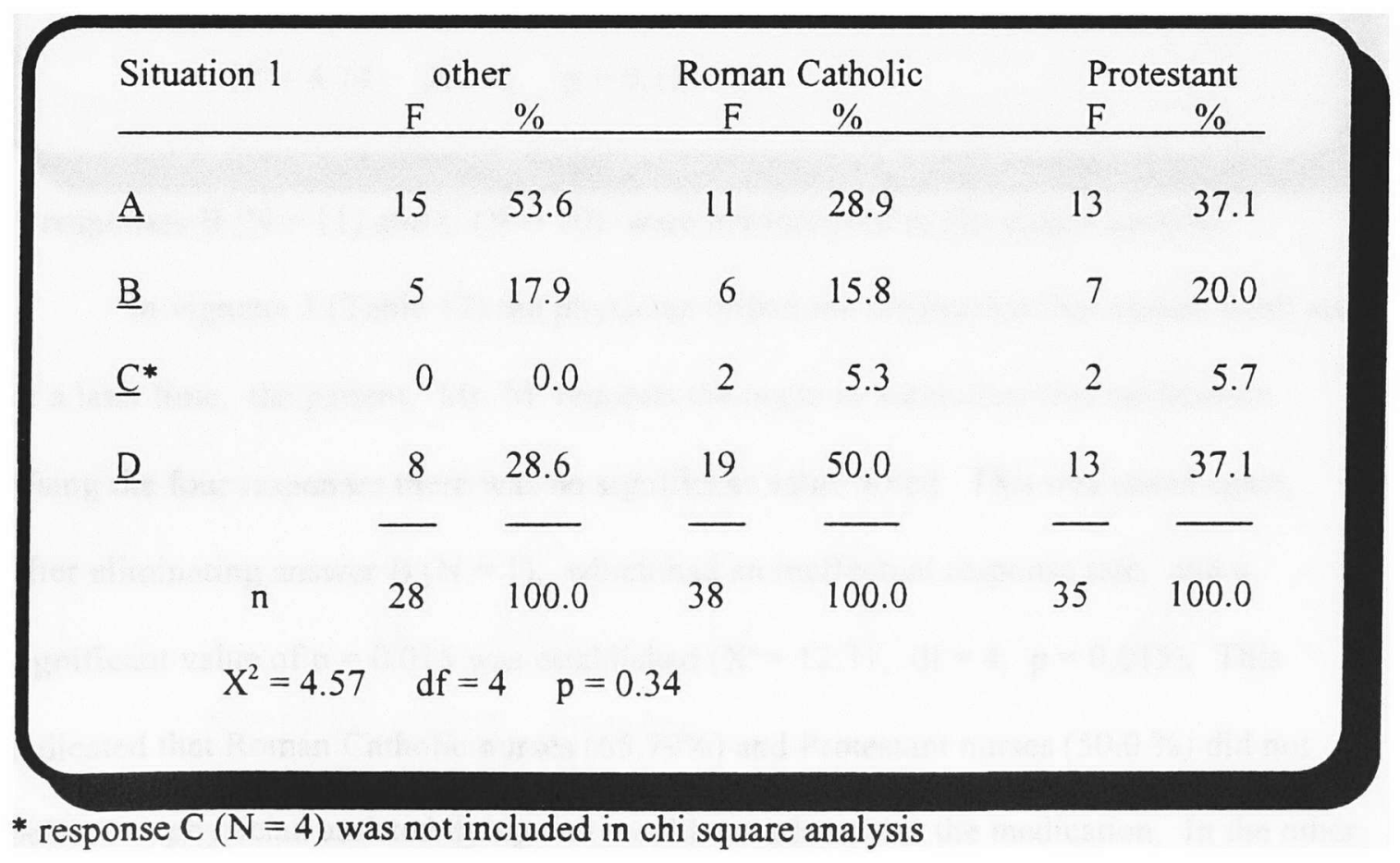


The nurses religions and their responses to vignette 2 is depicted in Table 16.

Responses $\mathrm{B}(\mathrm{N}=11)$ and $\mathrm{C}(\mathrm{N}=10)$ were eliminated due to the insignificant response rate. This vignette was also analyzed with all four responses and with two responses and no significant values were noted $\left(X^{2}=4.14, d f=2, p=0.13\right)$.

Table 16: Relationship between nurses religion and responses to vignette 2 .

\begin{tabular}{lccccccc} 
Situation 2 & \multicolumn{2}{c}{ other } & \multicolumn{2}{c}{ Roman Catholic } & \multicolumn{2}{c}{ Protestant } \\
& $\mathrm{F}$ & $\%$ & \multicolumn{2}{c}{$\mathrm{F}$} & $\%$ & $\mathrm{~F}$ & $\%$ \\
\hline$\underline{\mathrm{A}}$ & 13 & 46.4 & 9 & 23.7 & 11 & 31.4 \\
B $^{*}$ & 3 & 10.7 & 2 & 5.3 & 6 & 17.1 \\
$\underline{\mathrm{C}}^{*}$ & 2 & 7.1 & 5 & 13.2 & 3 & 8.6 \\
$\underline{\mathrm{D}}$ & & 10 & 35.7 & 22 & 57.9 & 15 & 42.9 \\
& $\mathrm{n}$ & $\overline{28}$ & $\overline{100.0}$ & $\overline{38}$ & $\overline{100.0}$ & $\overline{35}$ & $\overline{100.0}$ \\
& $\mathrm{X}^{2}=4.14$ & $\mathrm{df}=2$ & $\mathrm{p}=0.13$ & & & &
\end{tabular}

* responses $\mathrm{B}(\mathrm{N}=11)$ and $\mathrm{C}(\mathrm{N}=10)$ were not included in chi square analysis

In vignette 3 (Table 17) the physician orders the medication that causes death and at a later time, the patient, Mr. M. requests the nurse to administer this medication. Using the four responses there was no significant value noted. This was tested again after eliminating answer $\mathrm{B}(\mathrm{N}=1)$, which had an ineffectual response rate, and a significant value of $p=0.015$ was established $\left(X^{2}=12.31, d f=4, p=0.015\right)$. This indicated that Roman Catholic nurses (65.79\%) and Protestant nurses (50.0\%) did not believe in physician assisted dying and would not administer the medication. In the other 
category there was a relatively equal distribution across the three responses.

In situation 4 (Table 18) the nurses distinguish if profound suffering is sufficient justification for physician assisted dying. The nurses religion were analyzed with all four answers and no significance was found. The nurses religion was analyzed again with answers $\mathrm{B}(\mathrm{N}=4)$ and $\mathrm{C}(\mathrm{N}=12)$ collapsed for an accurate chi square test and a significant value of $\mathrm{p}=0.018$ was established $\left(\mathrm{X}^{2}=8.09, \mathrm{df}=2, \mathrm{p}=0.018\right)$. The Roman Catholic nurses (66.7\%) strongly believed that profound suffering was not a justification for physician assisted suicide. Only $27.3 \%$ of the nurses in the other category agreed, with $72.7 \%$ believing profound suffering was sufficient justification. The Protestant nurses responses demonstrated relatively equal distribution in answers $\mathrm{A}$ $(55.2 \%)$ and $\mathrm{D}(44.8 \%)$.

Table 17: Relationship between the nurses religion and their response to vignette 3

\begin{tabular}{lcccccc} 
Situation 3 & \multicolumn{2}{c}{ other } & \multicolumn{2}{c}{ Roman Catholic } & \multicolumn{2}{c}{ Protestant } \\
& F & $\%$ & F & & F & $\%$ \\
\hline A & 9 & 32.1 & 5 & 13.2 & 2 & 5.7 \\
B $^{*}$ & 0 & 0.0 & 0 & 0.0 & 1 & 2.9 \\
C & 8 & 28.6 & 8 & 21.1 & 5 & 42.9 \\
D & 11 & 39.3 & 25 & 65.8 & 17 & 48.6 \\
n & $\overline{28}$ & $\overline{100.0}$ & $\overline{38}$ & $\overline{100.0}$ & $\overline{35}$ & $\frac{100.0}{100.0}$
\end{tabular}

$$
X^{2}=12.31 \quad \text { df }=4 \quad p=0.015
$$

* response $\mathrm{B}(\mathrm{N}=1)$ was not included in chi square analysis 
Table 18: Relationship of nurses religion and their responses to vignette 4

\begin{tabular}{|c|c|c|c|c|c|c|}
\hline \multirow[t]{2}{*}{ Situation 4} & \multicolumn{2}{|c|}{ other } & \multicolumn{2}{|c|}{ Roman Catholic } & \multicolumn{2}{|c|}{ Protestant } \\
\hline & $\mathrm{F}$ & $\%$ & $\mathrm{~F}$ & $\%$ & $\mathrm{~F}$ & $\%$ \\
\hline$\underline{A}$ & 16 & 64.0 & 10 & 27.0 & 16 & 45.7 \\
\hline$\underline{B}^{*}$ & 1 & 4.0 & 1 & 2.7 & 2 & 5.7 \\
\hline$\underline{C}^{*}$ & 2 & 8.0 & 6 & 16.2 & 4 & 11.4 \\
\hline$\underline{D}$ & 6 & 24.0 & 20 & 54.1 & 13 & 37.1 \\
\hline $\mathrm{n}$ & 25 & 100.0 & .37 & 100.0 & 35 & 100.0 \\
\hline$X^{2}=8.09$ & $\mathrm{df}=2$ & $p=$ & & & & \\
\hline
\end{tabular}

* responses $\mathrm{B}(\mathrm{N}=4)$ and $\mathrm{C}(\mathrm{N}=12)$ were not included in chi square analysis

Table 19 represents the nurses religion and their response to legalization of physician - assisted dying for a competent, terminally ill adult. Although $53.5 \%$ would vote for legalization of $\mathrm{PAD}$ and $46.5 \%$ would vote against, there was no significance noted in relation to religions $\left(X^{2}=5.13, d f=2, p=0.08\right.$

The nurses religion was compared to the rating of pain relief in the patients they have cared for, demonstrated in Table 20. There was no significant value noted with all four responses separate or with responses 1 and 2 grouped $\left(X^{2}=4.14\right.$, df $\left.=4, p=0.39\right)$. A one way ANOVA on pain relief by religion was tested with no significant value established. 
Table 19: Relationship of nurses religion and their responses to legalization of PAD

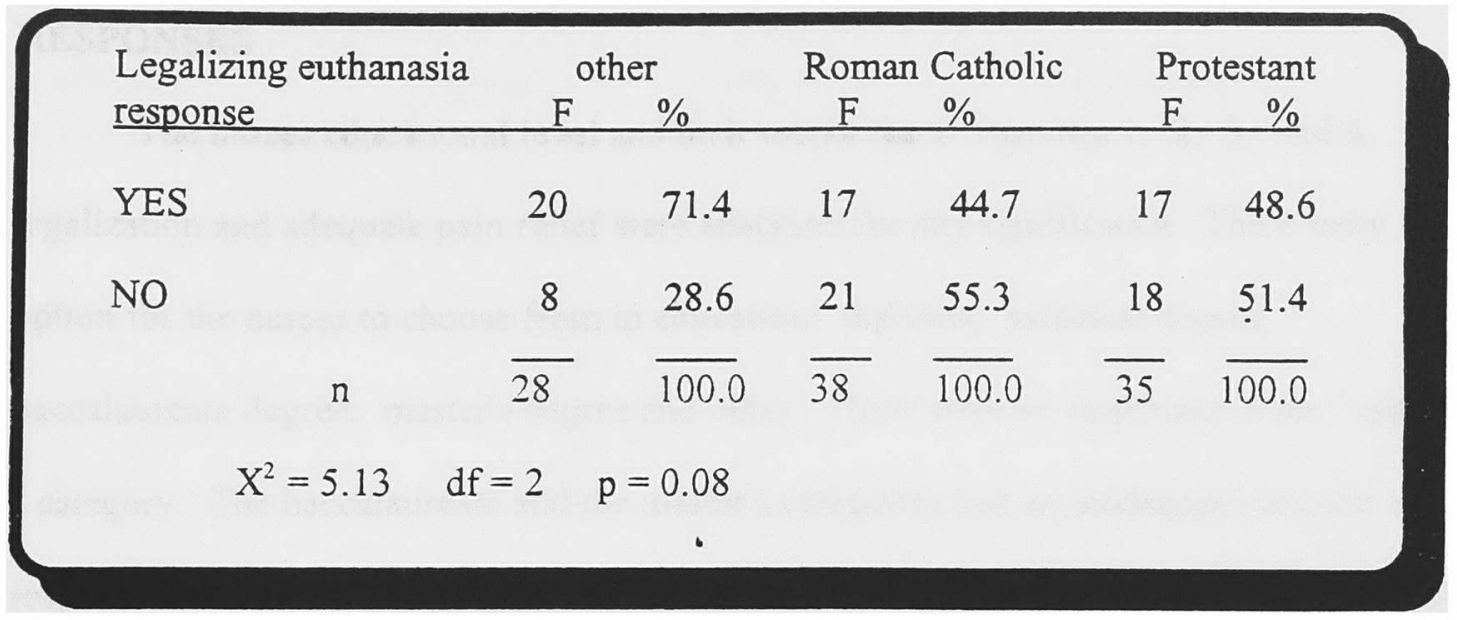

Table 20: Relationship between nurses religion and their responses to adequate pain relief

\begin{tabular}{|c|c|c|c|c|c|c|}
\hline \multirow{2}{*}{$\begin{array}{l}\text { Adequate physical } \\
\text { pain relief }\end{array}$} & \multicolumn{2}{|c|}{ other } & \multicolumn{2}{|c|}{ Roman Catholic } & \multicolumn{2}{|c|}{ Protestant } \\
\hline & F & $\%$ & $\mathrm{~F}$ & $\%$ & $\mathrm{~F}$ & $\%$ \\
\hline 1 , almost never & 1 & 3.7 & 1 & 2.6 & 3 & 8.6 \\
\hline $2 *$ & 5 & 18.5 & 4 & 10.5 & 7 & 20.0 \\
\hline 3 & 6 & 22.2 & 10 & 26.3 & 11 & 31.4 \\
\hline 4 , most of time & 15 & 55.6 & 23 & 60.5 & 14 & 40.0 \\
\hline $\begin{array}{c}n \\
X^{2}=4.14\end{array}$ & $\begin{array}{c}27 \\
d f=4\end{array}$ & $\begin{array}{l}100.0 \\
p=0.39\end{array}$ & 38 & 100.0 & 35 & 100.0 \\
\hline
\end{tabular}

* response $2(\mathrm{~N}=16)$ and $1(\mathrm{~N}=5)$ were combined in order to perform an adequate chi square 


\section{RELATIONSHIP BETWEEN EDUCATIONAL LEVEL AND NURSES RESPONSES}

The nurses educational level and their responses to vignettes $1,2,3$, and 4, legalization and adequate pain relief were analyzed for any significance. There were five option for the nurses to choose from in education: diploma, associate degree, baccalaureate degree, master's degree and other. There were no responses in the " other " category. The baccalaureate and the master's categories had an inadequate amount of responses so they were combined to perform a satisfactory chi square test.

The nurses level of education and their response to vignette $l$ are depicted in Table 21. There were no significant values found with all four responses. There was no change in significant values noted after eliminating answer $\mathrm{C}(\mathrm{N}=4)$, which had a minimal response rate $\left(X^{2}=5.57, \mathrm{df}=4, \mathrm{p}=0.23\right)$.

In situation 2 (Table 22) the nurses educational level and their responses were analyzed. There were no significant values established with all four responses included. There were also no significant values noted after eliminating answers $\mathrm{B}(\mathrm{N}=1)$ and $\mathrm{C}(\mathrm{N}$ $=31)$ which had ineffective response rates $\left(X^{2}=3.66, d f=2, p=0.16\right)$. 
Table 21: Relationship between nurses educational level and their response to vignette 1

\begin{tabular}{|c|c|c|c|c|c|c|}
\hline \multirow{2}{*}{ Situation 1} & \multirow{2}{*}{\multicolumn{2}{|c|}{$\begin{array}{l}\text { diploma } \\
\mathrm{F} \quad \% \\
\end{array}$}} & \multicolumn{2}{|c|}{ associate } & \multicolumn{2}{|c|}{ bacc, masters } \\
\hline & & & $\mathrm{F}$ & $\%$ & $\mathrm{~F}$ & $\%$ \\
\hline$\underline{\mathrm{A}}$ & 5 & 26.3 & 14 & 43.8 & 20 & 40.8 \\
\hline$\underline{B}$ & 2 & 10.5 & 7 & 21.9 & 9 & 18.4 \\
\hline$\underline{\mathrm{C}}^{*}$ & 0 & 0.0 & 2 & 6.3 & 2 & 4.1 \\
\hline D & 12 & 63.2 & 9 & 28.1 & 18 & 36.7 \\
\hline $\mathrm{n}$ & 19 & 100.0 & 32 & 100.0 & 49 & 100.0 \\
\hline$X^{2}=5.57$ & $\mathrm{df}=4$ & $p=0.23$ & & & & \\
\hline
\end{tabular}

* response $\mathrm{C}(\mathrm{N}=4)$ was not included in chi square analysis

Table 22: Relationship between nurses educational level and their response to vignette 2

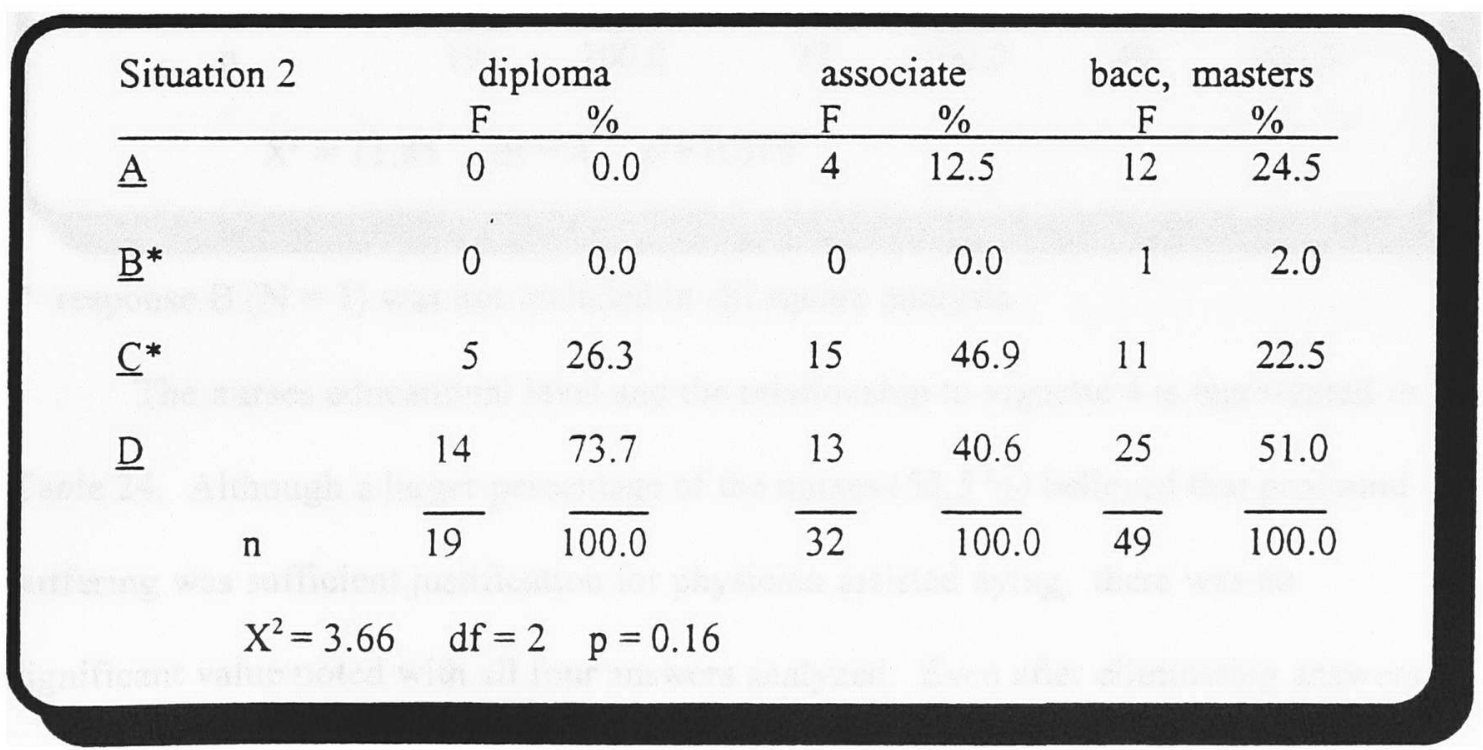

* responses $\mathrm{B}(\mathrm{N}=1)$ and $\mathrm{C}(\mathrm{N}=31)$ were not included in chi square analysis 
There was a significant value noted for vignette 3 (Table 23). The nurses educational level and their response to situation 3 (Pt. request nurse to administer medication) was analyzed with all four answers with a significant value of $p=0.04$ noted. The nurses educational level and their responses to situation 3 was analyzed again after eliminating answer $\mathrm{B}(\mathrm{N}=1)$, which had an ineffective response rate, with a significant value of $\mathrm{p}=0.02$ established $\left(\mathrm{X}^{2}=11.85, \mathrm{df}=4, \mathrm{p}=0.019\right)$.

Table 23: Relationship between nurses educational level and their response to vignette 3 -

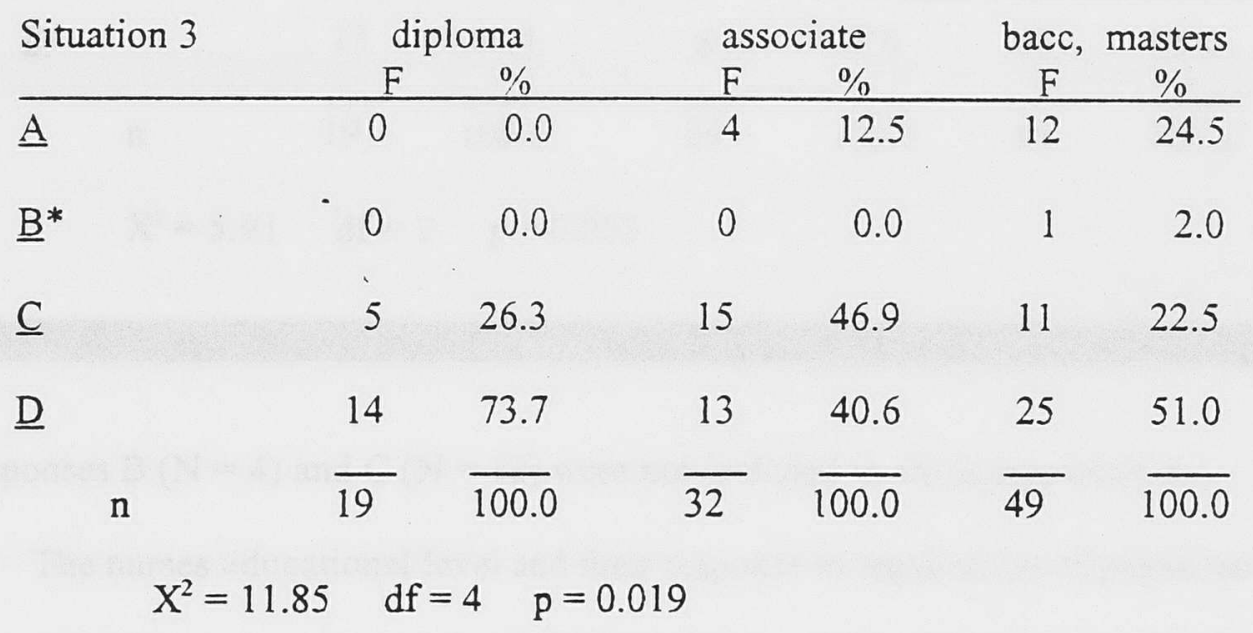

* response $\mathrm{B}(\mathrm{N}=1)$ was not included in chi square analysis

The nurses educational level and the relationship to vignette 4 is represented in Table 24. Although a larger percentage of the nurses (52.5\%) believed that profound suffering was sufficient justification for physician assisted dying, there was no significant value noted with all four answers analyzed. Even after eliminating answers B $(\mathrm{N}=4)$ and $\mathrm{C}(\mathrm{N}=12)$, which had insufficient response rates, chi square analysis 
revealed no significant values $\left(\mathrm{X}^{2}=5.91, \mathrm{df}=2, \mathrm{p}=0.052\right)$.

Table 24: Relationship between the nurses educational level and their response to vignette 4

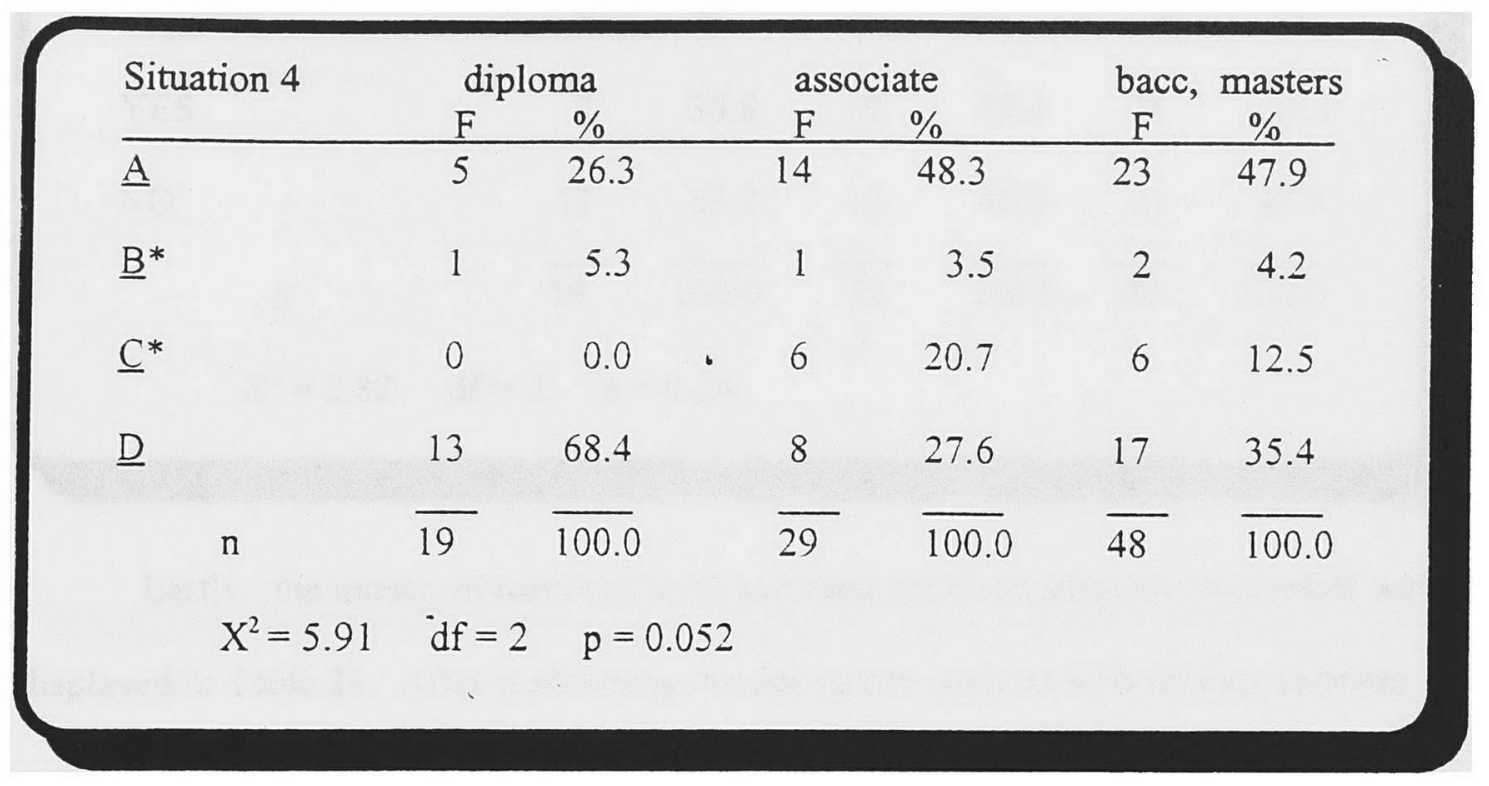

* responses $\mathrm{B}(\mathrm{N}=4)$ and $\mathrm{C}(\mathrm{N}=12)$ were not included in chi square analysis

The nurses educational level and their response to legalization of physician assisted dying for a competent, terminally ill adult is rendered in Table 25 . While fifty four per cent of the nurses would vote yes and $46 \%$ would vote against, there was no significance with chi square analysis between the nurses educational level and their beliefs on legalizing euthanasia $\left(X^{2}=2.82, d f=2, p=0.24\right)$. 
Table 25: Relationships of nurses educational level and their responses to legalization of PAD

\begin{tabular}{|c|c|c|c|c|c|c|}
\hline \multirow{2}{*}{$\begin{array}{l}\text { Legalizing euthanasia } \\
\text { response }\end{array}$} & \multicolumn{2}{|c|}{ diploma } & \multicolumn{2}{|c|}{ associate } & \multirow{2}{*}{$\begin{array}{r}\text { bacc, } \\
\mathrm{F}\end{array}$} & \multirow{2}{*}{$\begin{array}{c}\text { masters } \\
\%\end{array}$} \\
\hline & $\mathrm{F}$ & $\%$ & $\mathrm{~F}$ & $\%$ & & \\
\hline YES & 7 & 36.8 & 19 & 59.4 & 28 & 57.1 \\
\hline NO & 12 & 63.2 & 13 & 40.6 & 21 & 42.9 \\
\hline $\mathrm{n}$ & 19 & 100.0 & 32 & 100.0 & 49 & $\overline{100.0}$ \\
\hline $\mathrm{X}^{2}=2.82 \quad \mathrm{df}$ & & .24 & & & & \\
\hline
\end{tabular}

Lastly, the nurses educational level and their belief on adequate pain relief was displayed in Table 26. After performing the chi square analysis with all four answers and with answers 1 and 2 combined there were no significant values established. Chi square analysis revealed no relationship between the nurses educational level and their beliefs on adequate pain relief $\left(\mathrm{X}^{2}=3.10, \mathrm{df}=4, \mathrm{p}=0.54\right)$. A one way ANOVA was performed with no significant values noted. 
Table 26: Relationship between the nurses educational level and their response to adequate pain relief

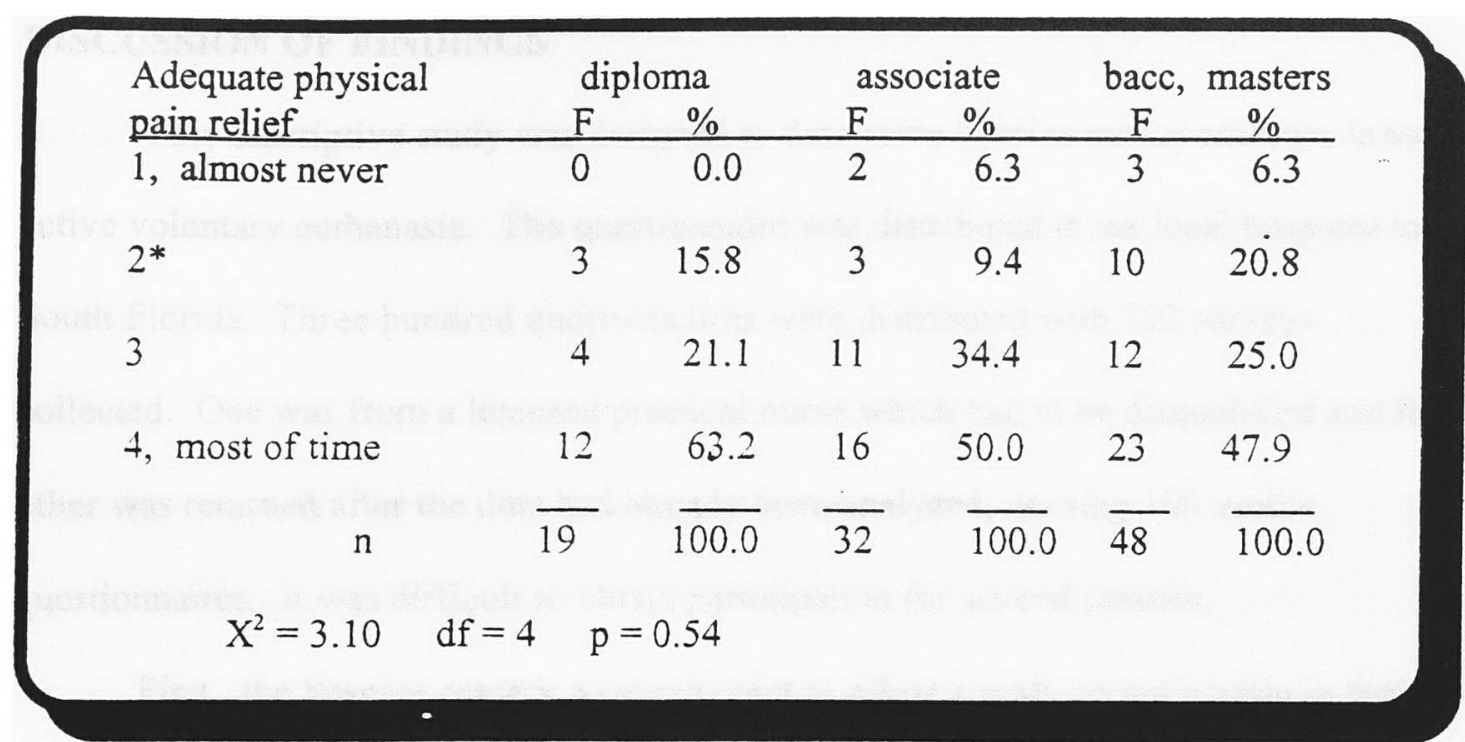

* response $2(\mathrm{~N}=16)$ and $\mathrm{l}(\mathrm{N}=5)$ were combined in order to perform an adequate chi square 


\section{CHAPTER V:}

\section{DISCUSSION}

\section{DISCUSSION OF FINDINGS}

This descriptive study was designed to determine hospice nurses attitudes towards active voluntary euthanasia. The questionnaire was distributed in six local hospices in South Florida. Three hundred questionnaires were distributed with 102 surveys collected. One was from a licensed practical nurse which had to be disqualified and the other was returned after the data had already been analyzed, leaving 100 usable questionnaires. It was difficult to obtain participation for several reasons.

First, the hospice centers were reluctant to allow a study on euthanasia in their facility. Many of the hospices stated their outlook on euthanasia before even reading the proposal. After discussing the proposal most hospices were more comfortable with the study, although there were still three hospices that rejected the study. This is understandable due to the controversial issue at hand and the position the hospice centers have within the community.

Second, the nurses were afraid that their place of work would read the questionnaires and somehow it would reflect on their employment. The majority of nurses were not familiar with research and were reluctant to participate. Many would not participate because they had to sign a consent form. They believed that they would be identified and exposed. This was later corrected with the approval of my research committee and participation increased. 
Lastly, the nurses did not understand the research impact they would be making with their participation. Many were not aware of the agile movement of active voluntary euthanasia within legislation. Even less were aware of the legislation in the state of Oregon.

The nurses that did participate documented some helpful insights of hospice nursing. It was noted that $53.4 \%$ (Table 6) of nurses supported AVE and $83 \%$ (Table 7) of the nurse would not administer the medication that would cause death. It was noted that age was a significant variable. The older nurses $50+(63.6 \%)$ were more strongly against euthanasia in situation 1 (Table 8$)$ than the nurses $21-40$ years old $(25.0 \%)$ and the $41-49$ year olds $(27.0 \%)$. The older nurses $(63.6 \%)$ also did not believe profound suffering was sufficient justification for active voluntary euthanasia (Table 11). Where as the nurses $21-40$ years old $(60.0 \%)$ and the nurses $41-49$ years old $(47.2 \%)$ believed suffering was enough justification for active voluntary euthanasia. Many of the nurses commented that once the patient was under hospice care they were not usually in any physical pain or had minimal physical pain. Some nurses did point out that they could control the physical pain well, but the emotional pain was very difficult to manage, therefore numerous patients suffer emotionally. There were significant findings noted with response to physical pain. The nurses of ages $50+(53.1 \%)$ and 21 $40(75.0 \%)$ believed that most of the time their patients were free of physical pain (Table 13). This is interesting because in the study by Miller (1992) $52.5 \%$ of the patients had suffered such unbearable symptoms prior to death that they had to be 
sedated during the last days of their lives. The responses of the nurses $41-49$ years old was more equally distributed across the ratings for pain.

The nurses religion made a significance when it came to administering the medication (Table 17) and with profound suffering as a justification for active voluntary euthanasia (Table 18). The Roman Catholic nurses (65.8\%) strongly opposed the medication administration more so than the Protestant nurses $(48.6 \%)$ and the "other" nurses (39.3). Also the Roman Catholic nurses (54.1\%) did not believe profound suffering was sufficient justification for AVE, whereas the Protestant (37.1\%) and "other" (24.0\%) nurses were more flexible. This correlates with other studies performed on nurses and physicians.(Cohen, et al., 1994; Preston, 1994; Shapiro, et al., 1994; and Young, et al., 1993). The other studies found that the nurses or physicians specialty and religion had an important influence on their decision to actively participate in euthanasia.

From an educational perspective the only significance found was the nurses reluctance to administer the medication which would cause death (Table 19). There were no other studies that tested this phenomena, therefore, there are no studies with which to compare. This indicated that whether the nurses were diploma educated or master's prepared they were not willing to administer the medication. Many of the nurses commented that administering this medication was the physician's obligation. Others believed that since the physician is the one who pronounces death, he or she should administered the medication. Few had no problem administering the medication if it was 
truly what the patient wanted.

Intriguingly, the only variable that made a significant impact on legalizing euthanasia was the nurses' age. The nurses $50+(70.0 \%)$ strongly opposed legalization, while the nurses $21-40$ (78.9\%) strongly supported legalization of euthanasia. Religion and educational level had no significance on the nurses votes for active voluatary euthanasia. Numerous studies have included questions about legislation that would legalize euthanasia ('Cohen, et al., 1994; Kuhse and Singer, 1993; Preston, 1994; Takeo, et al., 1991) with similar results. No other study was found that analyzed the relationships between age, religion and educational level on the participants response to legalization of euthanasia.

In summary numerous significances were established between the nurses age, religion and educational level. This study did reveal useful data for further research.

\section{IMPLICATIONS}

There are many implications of this study. Active voluntary euthanasia is an issue that will continue to be a sequel in providing care for the terminally ill patient. Hospice nurses hold a unique perspective of death and dying because the patient does seek their services for the sole purpose of dying, where as the hospital nurse works in an acute care setting where the patient is there to seek all the medical care they can to prevent them from dying. Still and all, should active voluntary euthanasia become legal there would definitely be a direct impact on nursing and their patient care roles. Despite the nurses personal opinion, 
they may be called to stay with the patient through the administration of the medication or may even be asked to give the medication. Therefore, it is critical that not only hospice nurses but all nurses become educated on the issues of active voluntary euthanasia or physician assisted dying / suicide.

On the other hand, although it may not be fair to force nurses to set their beliefs aside, it is also not just to impose one's belief on another. There have recently been more suicide - murder cases related to terminally ill spouses than previously seen. What makes a person reach this point? They obviously must see no other alternative to a peaceful death. It is sad to believe that with all the technology and medical advancement this country can provide, it is nearly impossible to die in peace with dignity. Although religiously the nurses and physicians may oppose euthanasia, if the patient chooses this option, is it not the patients right to an autonomous decision based on " their " life experiences. Therefore, the public must be educated on their options and rights related to death and dying, for example, the advantages of having an advanced directive, designating surrogate, hospice care, and support groups that can provide unbiased answers on death and dying issues.

Active voluntary euthanasia affects everyone. It affects the health care worker and facilitators because they are active participants, it affects the patient because it is their life and it affects society because it is an issue that makes people question their morals and values. The administration of the medication should not be the issue at hand, but rather the effect of death and dying itself. While nurses and physicians are faced 
with death and dying daily, few see it as a natural part of life but rather as failure. This should be an indication for the desperate need to incorporate more education on death and dying in nursing and medical schools.

The concept of suffering significantly affects the desires for active voluntary euthanasia.

Therefore, adequate physical and psychological relief must be addressed and provided so that patients will not view euthanasia as the only alternative to a peaceful death. This implication could also be applied within the nursing schools and as continuing education credits for nurses and physicians. The need for adequate pain relief without the fear of a hasty death is an issue that most nurses encounter. Do you give the patient the adequate amount of medication to relieve them of pain even if it hastens death? Or do you give the patient a lesser amount and allow them to suffer a little until they die? Murphy and Price (1995) wrote an article on taking an active approach to end of life care. In this article they focus on simple, straightforward conceptual and communicative approaches that the nurses can and will do for the dying patient. They call this approach "ACT" which stands for aggressive comfort treatment. This is one of the many new innovative views on adequate pain relief, but it must be incorporated into practice to have an impact. Also, the ANA's position statement on promotion of comfort and relief of pain in dying patients (1991) states the following: A. Nurses should not hesitate to use full and effective doses of pain medication for the proper management of pain in the dying patient. B. The increasing titration of medication to achieve adequate symptom 
control, even at the expense of life, thus hastening death secondarily, is ethically justified.

\section{LIMITATIONS OF STUDY}

The study could have had a larger number of participants. The consent form was the study's downfall because it frightened many nurses away. With the increased diversity in South Florida, ethnicity should have been included in the questionnaire to determine any significant differences. Instead of recruiting the participants at their work place, going through the hospice nurses associations may have had a greater impact on the participation rate. The study also focused on South Florida hospice nurses only, where as other parts of the country may have a different perspective on active voluntary euthanasia. I recommend this study to be replicated on different specialties of nursing and to include ethnicity. On such controversial issues consent forms may not be advantageous.

\section{CONCLUSION}

Harrison, Burnside and Beauchamp (1993) wrote an article on euthanasia and decisions about life and death. In this article there were two letters that seized my attention. The first letter was written to the editor from a physician in Illinois that stated the following:

As one who has had a long, full, rich life of practice, service and fulfillment, whose days are limited by the rapidly growing, highly malignant sarcoma of the peritoneum, whose hours, days, and nights are ranked by 
intractable pain, discomfort, and insomnia, whose mind is often beclouded and disoriented by soporific drugs, and whose body is assaulted by needles and tubes that can have little effect on the prognosis, I urge medical, legal, religious and social support for a program of voluntary euthanasia with dignity. Prolonging the life of such a patient is cruelty. It indicates a lack of sensitivity to the needs of a dying patient and is an admission of refusal to focus on the subject that the healthy cannot face. Attention from the first breath of life through the last breath is the doctor's work; the last is no less important than the first.

Consent by the patient with a clear understanding of this fact, by the patient's immediate family, by the family physician, lawyer, minister, or friend should violate no rules of social conduct. There is no reason for the erratic, painful course of the final events of life to be left to blind nature. Man chooses how to live; let him choose how to die. Let man choose when to depart, where, and what circumstances the harsh winds that blow over the terminus of life must be subdued.

This is an obvious cry for help for new legislation on death and dying issues. The second letter focused on the hypocritical differences between active and passive euthanasia. This portion of the article questions the differences and its humanness. When surgery is denied (the doctor) must try to keep the infant from suffering while natural forces sap the baby's life away. As a surgeon whose natural inclination is to use the scalpel to fight off death, standing by and 
watching a salvageable baby die is the most emotionally, exhausting experience I know. It is easy at a conference, in a theoretical discussion, to decide that such infants should be allowed to die. It is altogether different, to stand by in the nursery and watch as dehydration and infection wither a tiny being over hours and days. This is a terrible ordeal for me and the hospital staff - much more than for the parents who never set foot in the nursery.

I can understand why some people are opposed to all euthanasia, and insist that such infants must be allowed to live. I think I can also understand why other people favor destroying these babies quickly and painlessly. But why should anyone favor letting "dehydration and infection wither a tiny being over hours and days?" The doctrine that says that a baby may be allowed to dehydrate and wither, but may not be given an injection that would end its life without suffering, seems so patently cruel as to require no further refutation. The strong language is not intended to offend, but only to put the point in the clearest possible way.

My second argument is that the conventional doctrine leads to decisions concerning life and death made on irrelevant grounds.

Consider again the case of the infants with Down's syndrome who need operations for congenital heart defects unrelated to the syndrome to live. Sometimes, there is no operation, and the baby dies, but when there is no such defect, the baby lives on. Now, an operation such as that to remove an intestinal 
obstruction is not prohibitively difficult. The reason why such operations are not performed in these cases is, clearly, that the child has Down's syndrome and the parents and doctor judge that because of that fact it is better for the child to die.

But notice that the situation is absurd, no matter what view one takes of the lives and potentials of such babies. If the life of such an infant is.worth preserving, what does it matter if it needs a simple operation? Or, if one thinks it better that such a baby should not live on, what difference does it make that it happens to have an unobstructed intestinal tract? In either case, the matter of life and death is being decided on irrelevant grounds. It is the Down's syndrome, and not the intestines, that is the issue. The matter should be decided, if at all, on that basis, and not be allowed to depend on the essentially irrelevant questions of whether the intestinal tract is blocked.

What makes this situation possible, of course, is the idea that when there is an intestinal blockage, one can "let the baby die," but when there is no such defect there is nothing that can be done, for one must not "kill" it. The fact that this idea leads to such results as deciding life and death on irrelevant grounds is another good reason why the doctrine should be rejected.

One reason why so many people think that there is an important moral difference between active and passive euthanasia is that they think killing someone is morally worse than letting someone die. But is it? Is killing, in itself, worse than letting die? 
These are the moral question that nurses, physicians and all society must ask itself. Why is it justifiable to allow a person to die from dehydration, starvation and controllable circumstances, where the person may take from hours to weeks to die? Why is active voluntary euthanasia not justifiable to the patients that request it? Why it is acceptable to society to allow a person to suffer until death occurs rather than give a medication that would end their suffering? If the issue is that we are " playing God" with active voluntary euthanasia, then are we not " playing God," when we utilize medical technology to prolong death. This system is designed to save lives at all cost, but this same system makes it difficult for a patient to die naturally. Even with advanced directives patient's have a difficult time having their rights to die respected. I believe that all humans have a strong will to live and death is only an option when life has become unbearable. There is a desperate need for parity between living and dying. 


\section{REFERENCES}

Anderson, J. G. and Caddell, D. P. (1993). Attitudes of medical professionals towards euthanasia. Social Science Medical, 37 (1), $105-114$.

Battin, M. (1992). Voluntary euthanasia and the risks of abuse: Can we learn anything from the Netherlands? Law Medicine \& Health Care, 20 (1-2), 133 - 143.

Baume, P. and O'Malley, E. (1994). Euthanasia: Attitudes and practices of medical practitioners. The Medical Journal of Australia, 161 (2), 137, 140, $142-144$.

Cohen, J. S., Fihn, S. D., Boyko, E. J., Jonsen, A. R., and Wood, R. W. (1994). Attitudes towards assisted suicide and euthanasia among physicians in Washington State. The New England Journal of Medicine, 331 (2), 89 - 94.

Coyle, N. (1992). The euthanasia and physician - assisted suicide debate: Issues for nursing. Oncology Nursing Forum, 19 (7), 41 - 46.

Davis, A. J., Davidson, B., Hirschfield, M., Lauri, S., Lin, J. Y., Norberg, A. Phillips, L., Pitman, E., Shen, C. H., Laan, R. V., Zhang, H. L., and Ziv, L. (1993). An international perspective of active euthanasia: Attitudes of nurses in seven countries. International Journal of Nursing Studies, 30 (4), $301-309$.

Davis, A. J. and Slater, P. V. (1989). U. S. and Australian nurses' attitudes and beliefs about the good death. Image: Journal of Nursing Scholarship, 21 (1), 34 - 39 .

Devettere, R. J. (1989). Reconceptualizing the euthanasia debate. Law Medicine and Health Care, 17 (2), $145-155$.

DeWachter, M. A. M. (1992). Euthanasia in the Netherlands. The Hastings Center 
Report, 22 (2), $23-28$.

Dworkin, G. (1988). The Theory and Practice of Autonomy. New York: Cambridge University Press.

Evans, S. A. (1990). Who lives, who dies, who decides? Heart \& Lung: Journal of CriticalCare, 19 (5), 21A - 27A.

Falvcett, J. (1993). Analysis and Evaluation of Nursing Theories. Pennsylvania: F. A. Davis Co.

Florida Patient Bill of Rights and Responsibilities, s 381.026 (1992).

Grant, A. (1993). Questions of life and death. The Canadian Nurse, $\underline{89}$ (5), 31 - 34.

Guarino, K. S. and Antoine, M. P. (1991). The case of Nancy Cruzan: The supreme court's decision. Critical Care Nurse, 11 (1), 32, $34-36,38$ - 40.

Haddad, A. M. (1991). Where do you stand on euthanasia? $\underline{\mathrm{RN}}, \underline{12}$ (2), 38 - 43.

Harrison, F., Burnside, J., and Beauchamp, T. (1983). Heath and Human Values. New Haven: Yale University Press

Hogue, E. E. (1990). Withholding nutrition and hydration from an incompetent: Implications. Pediatric Nursing, 16 (5), $474-475$.

Humphry, D. (1991). Final Exit: the practicalities of self - deliverance and assisted suicide for the dying. Melbourne: Penguin.

Jansson, L. and Norberg, A. (1989). Ethical reasoning concerning the feeding of terminally ill cancer patients. Cancer Nursing, 12 (6), 352 - 358.

Johnson R. A. and Weiler, K. (1990). Aid - in - dying: Issues and implications for 
nursing Journal of Professional Nursing, 6 (5), 258 - 264.

Knott, J. E., Ribar, M. C., Duson, B. M. and King, M. R. (1989). Thanatopics: Activities and Exercises for Confronting Death. Massachusetts: Lexington Books.

Kowalski. S. (1993). Assisted suicide: Where do nurses draw the line? Nursing \& Health Care, 14 (2), $70-76$.

Kuhse, H. and Singer, P. (1989). The quality / quantity - of - life distinction and its moral importance for nurses. International Journal of Nursing Studies, 26 (3), $203-212$.

Kuhse, H. and Singer, P. (1993). Voluntary euthanasia and the nurse: an Australian survey. International Journal of Nursing Studies, 30 (4), $311-322$.

Lee, D. K. P., Swinburne, A. J., Fedullo, A. J. and Wahl, G. W. (1994).

Withdrawing care: Experience in a medical intensive care unit. Journal of the American Medical Association, 271 (17), $1358-1361$.

Life Prolonging Procedure Act, s 765.309 (1990).

Light, K. and Connelly, R. (1989). Is the ANA guilty of paternalism in its guidelines on withdrawing or withholding food and fluid? Nursing Forum, $\underline{3}$ (4), $19-23$.

Mappes, T. A. and Zembaty, J. S. (1991). Biomedical Ethics. New York: McGraw Hill Inc.

Marsden, C. (1990). Who should decide? Heart \& Lung: Journal of Critical Care, 19 (6), $687-689$. 
Menzel, P. T. (1992). Some ethical costs of rationing. Law, Medicine \& Health Care, $\underline{20}(1-2), 57-65$.

Meyer, C. (1993). 'End - of - life' care: Patients' choices, nurses' challenges. American Journal of Nursing, 93 (2), $40-47$.

Miller, R. J. (1992). Hospice care as an alternative to euthanasia. Law, Medicine \& Health Care, $20(1-2), 127-132$.

Murphy, P. A. and Price, D. M. (1995). 'ACT' Taking a positive approach to end - of - life care. American Journal of Nursing, 12 (3), 42 - 43.

Nurse's Handbook of Law and Ethics. (1992). Library of Congress Cataloging in Publication Data.

Paradis, L. F. (1985). Hospice Handbook: A Guide for Managers and Planners. Aspen Publications: Maryland.

Potter, P. and Perry, A. (1993). Fundamentals of Nursing. St. Louis: Mosby. Preston, T. A. (1994). Professional norms and physician attitudes towards euthanasia. The Journal of Law, Medicine \& Ethics, 22 (1), 36 - 40.

Rigter, H. (1989). Euthanasia in the Netherlands: distinguishing facts from fiction. The Hastings Center Report, 19 (1), S31 - S32.

Ringerman, E. S. and Koniak - Griffin, D. (1992). A reexamination of euthanasia: Issues raised by Final Exit. Nursing Forum, 27 (4), 5- 8, 34.

Rushton, C. H. and Hogue, E. E. (1993). When parents demand "everything". Pediatric Nursing, $\underline{19}$ (2), $180-183$. 
Savage, T. A., Cullen, D. L., Kirchhoff, K. T., Pugh, E. J. and Foreman, M. D. (1987). Nurses' responses to do - not - resuscitate orders in the neonatal intensive care unit. Nursing Research, $\underline{36}$ (6), $370-373$.

Schraff, S. H. (1984). Hospice: The Nursing Perspective. New York: NLN.

Shapiro, R. S., Derse, A. R., Gottlieb, M., Schiedermayer, D. and Olson, M. (1994). Willingness to perform euthanasia: a survey of physician attitudes. Archives of Internal Medicine, 154 (5), 575 - 584.

Solomon, M. Z., O'Donnell, L., Jennings, B., Guilfoy, V., Wolf, S. M., Nolan, K., Jackson, R., Koch - Weser, D., and Donnelley, S. (1993). Decisions near the end of life: Professional views on life - sustaining treatments. American Journal of Public Health, $\underline{83}$ (1), $14-22$.

Takeo, K., Satoh, K., Minamisawa, H., and Mitoh, T. (1991). Health workers' attitudes toward euthanasia in Japan. International Nursing Review, $\underline{38}$ (2), 45 48.

Weir, R. F. (1992). The morality of physician assisted suicide. Law. Medicine \& Health Care, $20(1-2), 116-126$.

Wold, J. L. (1992). The living will: Legal and ethical perspectives. Journal of Neuroscience Nursing, 24 (1), $50-53$.

Young, A., Volker, D., Rieger, P. T., and Thorpe, D. M. (1993). Oncology nurses' attitudes regarding voluntary, physician - assisted dying for competent, terminally ill patients. Oncology Nursing Forum, 20 (3), 445 - 451. 
Appendix I

Research Protocol

Title of the Project: Hospice Nurses Attitude's on Active Voluntary Euthanasia Responsible Investigator: Belinda Arjona Godfrey, BSN, RN

Objectives of the Project:

A. To identify hospice nurses attitudes towards active voluntary euthanasia or physician - assisted suicide.

B. To identify to what extent hospice nurses are willing to participate in active voluntary euthanasia or physician - assisted suicide.

C. To determine the relationship between hospice nurses demographic characteristics (age, religion, education) and their attitudes towards active voluntary euthanasia or physician - assisted suicide.

Project Beginning Date and Completion Date: May, 1995 - Sept, 1995 pending approval from appropriate committees.

Nature of Contact With Subjects Which Could Create Risks or Provide Benefit:

A. Risk: Subjects may recall unpleasant past experiences regarding patients whose comfort and condition were difficult to manage.

B. Benefit: Subjects may benefit from the knowledge that they are making a contribution to the body of knowledge concerning active voluntary euthanasia.

Literature or Other Data Regarding Procedure as Established and Relatively Safe:

This research method is an established and safe design. Written questionnaires are probably the most common means of collecting data. When questionnaires are used, all subjects are asked to respond to exactly the same questions, in exactly the same order, and have the same set of options for their responses (Polit and Hungler, 1983). Young, et al. (1993) studied oncology nurses attitudes regarding voluntary, physician assisted dying for competent, terminally ill patients. Two thousand oncology nurses were surveyed by using the Nurse's Attitudes Regarding Physician - Assisted Dying (NARPAD) Questionnaire. The research finding indicated that many oncology nurses favored physician assisted dying, but were reluctant to administer the medication.

The Nurse's Attitudes Regarding Physician - Assisted Dying Tool will be used in this 77 
study. Content validity was established by a panel of two ethicists and by an oncology nurse specialist with extensive experience in the care of terminally ill patients with cancer. The level of significance of 0.05 will be considered acceptable. Reliability will be done by test - retest method. The test will be administered to a group of hospice nurses who work in six South Florida hospice centers. A 0.80 reliability coefficient will be considered satisfactory.

\section{How Subjects Will Be Selected:}

Subjects will be a convenience sample of registered nurses who give consent to participate in the study. The nurses will have had a minimum of six months experience in hospice nursing.

\section{Environment for Subject's Contact:}

The five hospice centers in South Florida will be the environment in which the hospice nurses will be contacted. The questionnaires will be filled out by the subjects in the privacy of their homes or the hospice center.

Name and Qualifications of Person Having Contact With Subjects:

Investigator: Belinda Arjona Godfrey, BSN, RN

\section{MSN Candidate}

6 years total nursing experience

1 year pediatric neurology

4 years pediatric intensive care unit

1 year home health nursing

Names and Qualifications of Persons Handling the Data and Method to Ensure Confidentiality of Data:

Investigator only, Belinda Arjona Godfrey, BSN, RN. No names will be used on the instrument. Only code numbers will be used to identify the subject. Consent forms will be kept on separate file.

Financial Aspects of the Project:

A. Source of funds to support the project: Investigator will supply necessary funds.

B. Cost to subjects: There will be no cost to the subjects.

C. Renunciation or reward for participation: There will be none. 


\section{Method of Obtaining Legally Informed Consent:}

Subjects who volunteer to participate in the study will receive a cover letter attached explaining the purpose of the research study. Signing of the consent form was made optional due to the subject at hand with the approval of the committee. The signed consent forms will be kept separate.

\section{Manner in Which Subjects Will Be Debriefed About the Research When Their}

\section{Participation is Terminated:}

After completion of the study the hospice centers involved in the study will receive a thank you letter and will be notified of the journal with the publication. A copy of the thesis will be place in the library of the north campus of Florida International University in Miami, Florida. 



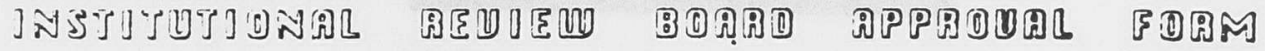

\section{FLDRIDA INTERNATIONAL UNIUERSITY \\ Uniuersity Park Campus \\ Miami, Florida 33199}

This is to cartify that the program listad below has been roulewed and

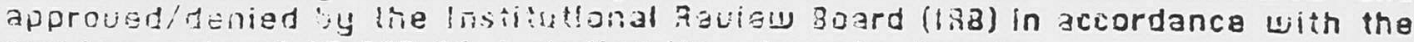

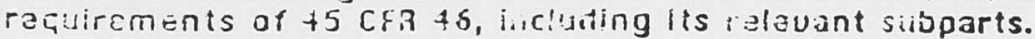

Principal InvastigatoriProjact Diractor: Belinda Ariona Godfrey

Title of Application: Hospice Nur'ses' Attitudes on Active Voluntary

Euthanasia or Phvsician-tssisted Suicide

Rgency Submitted to:

Proposal Identiflcation Number (if auallable):

Certificate of IRB:

$6 / 29 / 95$ Date of IRB Review and Approua/Denial Full Board Reulew $\mathrm{XX}$ Expedited Review

Comments: Project approved.

Ang problems should be Immediately brought to the attention of the IRB Council

The official signing below certifles that the information on this form is correct and the institution assumes responsibility for assuring future reulews, approvals, and submisslons of gertification.

Kat k k to

Kart G. Ktoeck, Chalmerson, IRB Committee

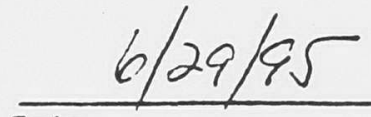

Date 


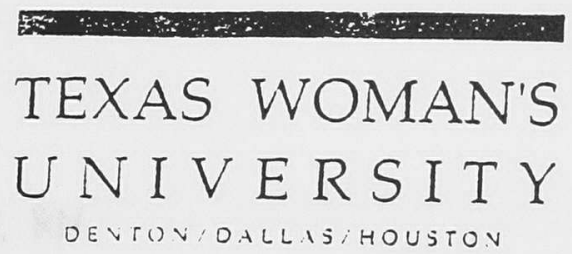

COLEECE CF \LRSINC

Hutusiun Cinicr

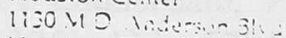

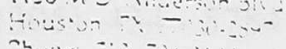

April 19, 1395

Belinda Godfrey, BSN, RN

Dear Belinda.

The purpose of this letter is to give you permission to use the Nursing Attitudes Regarding Physician Assisted Dying (NARPAD) questionnaire in your research siudy entitled "Hospice Nurses' Attitudes on Active, Voluntary Euthanasia." This is a copyrighted instrument. The conditions of using the questionnaire are that:

(1) the authors (Anne Young. Deborah Volker, Paula Rieger, and Deborah Thorpe) be given recognition for instrument development.

(2) a report of your completed study be sent to us.

As we discussed, your second research question regarding justifications for active, voluntary euthanasia may be difficult to answer with information from this questionnaire. $2109]$.

If we can be of further assistance, please do not hesitate to contact us [(713) 794 -

Sincerely.

Anne Young, Ed.D., RN

Associate Professor 


\section{Appendix IV}

Sept. 5, 1995

Belinda Arjona Godfrey, BSN, RN

Hospice Care Center

address.

FL. 34996

Dear Name of Education Director

Enclosed is a research proposal for review at Hospice Care center to conduct a research study on hospice nurses attitudes on active voluntary euthanasia or physician - assisted suicide. The written consent does not have to be signed, it just provides the nurses with more information about the study. All requirements regarding human subject protection will be implemented. This research study has been reviewed and approved by the research review board of Florida International University.

The research to be conducted is for a thesis, a requirement from the Florida International University MSN curricula.

Please consider this request to grant permission for the use of your nurses in the hospice center. Your acceptance will be greatly appreciated.

Sincerely,

Belinda Arjona Godfrey, BSN, RN 


\section{Appendix V \\ ATTENTION RN'S}

IF YOU HAVE 6 MONTHS EXPERIENCE IN HOSPICE

NURSING AND WOULD LIKE YOUR OPINIONS TO BE HEARD, WE NEED YOU.

WE ARE REQUESTING YOUR PARTICIPATION IN AN ANONYMOUS RESEARCH STUDY. YOUR RESPONSES WILL BE ONE OF THE 100 QUESTIONNAIRES COLLECTED FROM HOSPICE NURSES IN SOUTH FLORIDA. NO SINGLE PARTICIPANT WILL EVER BE IDENTIFIED.

THE QUESTIONNAIRE WILL TAKE A MAXIMUM OF 10 MINUTES TO COMPLETE. COLLECT QUESTIONNAIRE FROM NAME OF DESIGNEE.

JUST MAIL BACK IN THE SELF STAMPED ENVELOPE PROVIDED. YOU DO NOT HAVE TO SIGN THE CONSENT, IT JUST PROVIDES YOU WITH INFORMATION ABOUT THE STUDY.

YOUR INPUT IS DESPERATELY NEEDED.

DEADLINE SEPT. 30, 1995 


\section{Dear Hospice Nurses}

I would like to invite you to participate in a research study. This study is designed to explore and describe hospice nurses' attitudes on active voluntary euthanasia or physician assisted suicide. This study consist of a questionnaire with four vignettes, some demographic data and an awareness and opinion section.

This study will be completely anonymous. The questionnaire may take a maximum of twenty minutes to complete. Your insights are the key to this study.

As many of you know, medical care in the United States is changing dramatically. Active voluntary euthanasia has already become legal in the state of Oregon and California and Washington State are actively seeking legalization. Many times, as hospice nurses, your patients are verbalizing to you their needs and desires during their death and dying stages. Because you are in a unique situation with the terminally ill patient and family, you encounter more ethical dilemmas on death and dying than most nurses on a daily basis.

I would greatly appreciate your help into the insight your patients have offered you, and your feelings and views on active voluntary euthanasia. This information will help provide a foundation for further studies on active voluntary euthanasia.

Thank you very much for your participation. Please feel free to contact me if you need any further information or if I can assist you in any way.

Very truly yours,

Belinda Arjona Godfrey, RN, BSN 
Appendix VII

\section{INFORMED CONSENT} Suicide

Hospice Nurses Attitudes on Active Voluntary Euthanasia or Physician Assisted

I freely and voluntarily consent to be a participant in the research project entitled, Hospice Nurses Attitudes on Active Voluntary Euthanasia or Physician Assisted Suicide, to be conducted from May, 1995 through Sept, 1995, with Belinda Arjona Godfrey as the Principal Investigator.

I understand that the purpose of this research is to explore hospice nurses attitudes on active voluntary euthanasia or physician assisted suicide.

I understand that the research procedure will be as follows: A questionnaire will be given to me to fill out. The questionnaire is anonymous. I have been told that my responses will be kept strictly confidential. I understand that the questionnaire will take a maximum of twenty minutes to complete. I understand that this research has minimal or no known risks of harm or discomfort. I have been explained that I must complete the questionnaire alone in order to prevent biases. I understand I am not to discuss the questionnaire or the subject matter with my peers until the study has been completed.

I understand that the potential benefit of participating in this research project is the insight into nurses perspectives and perception on active voluntary euthanasia and to provide a foundation for further studies.

I understand that I may withdraw my consent and discontinue participation in this research project at any time with no negative consequences. I have been given the right to ask questions regarding the research study and any questions have been answered to my satisfaction.

I understand that if I desire further information about this research, I should contact Belinda A. Godfrey, RN, BSN at 434-5754 or Linda Simunek, RN, PhD at 940-5971. I have been offered a copy of this consent form.

I have read, understood and agreed to the above consent.

Participant's signature

Date

I have explained and defined in detail the research procedure in which the participant has agreed to participate and have offered him / her a copy of this consent form.

Principal Investigator's signature Date 


\section{Appendix VIII \\ NURSING ATTITUDES REGARDING \\ PHYSICIAN ASSISTED DYING}

INSTRUCTIONS: Please fill in the blank or check the appropriate response for the following questions. Select only one response per question.

1. GENDER Female Male

2. AGE Years

3. STATE IN WHICH YOU PRACTICE

4. BASIC LEVEL OF NURSING EDUCATION

Associate Degree
Diploma
HIGHEST LEVEL OF ED
Associate Degree
Diploma
Doctoral Degree
Baccalaureate Degree Other, Please specify

\section{HUGUEST LEVEL OF EDLCATION}

6. YEARS IN NURSING PRACTICE

\section{Baccalaureate Degree \\ Master's Degree \\ Other. Please specify} Years

7. YEARS AS A PRACTICING HOSPICE NURSE Years

\section{EMPLOYMENT STATUS}

Full time

Unemployed

9. PRIMARY FUNCTIONAL AREA
Part time

Retired

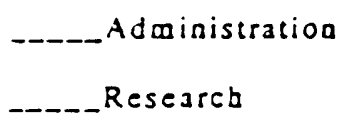
Education Patieat Care Other, please specify

10. PRIMARY POSITION

\begin{tabular}{l} 
Staff Nurse \\
$\ldots \ldots$ Cliaician \\
- Educator \\
$\ldots$ Supervisor \\
O- Researcher \\
\hline
\end{tabular}

_Education
Patieat Care


11. PATIENT POpUlation

—_None $\quad$ Adult

12. PRIMARY PRACTICE SETTING

$\begin{array}{ll}\text { Hospital } & \text { Outpatient Ambulatory Care Clinic } \\ \text { Hospice } & \text { Public Health/Community Nursing } \\ \text { Home Care } & \text { Scbool of Nursing } \\ \text { Pbysician's Office } & \text { Private/Group Practice } \\ \text { Compreheasive Cancer Center }\end{array}$

13. PRIMARY AREA OF PRACTICE

Cbemotherapy
Biotherapy
Surgical Oncology
GYN Oncology

14. RELIGIOUS AFFILIATION

Agnostic
Sewish
Roman Catbolic

Hematology/Oncology
Radiation Oncology
Head and Neck Oncology
Otber. Please specify

Atbeist

Protestant

Other. Please specify

INSTRUCTIONS: Please read each of the situations. Answer the quextions that follow the situation by circling the respoose that most elosely reflects the decision you would make in that situation. SELECT ONLY ONE RESPONSE. After each siousion, there is an are where you may commeat on the situation if you wish.

DEFINITIONS: Words used in this study will be defined as follows:

Physician assisted dying-medical procedure that will hummely terminate the life of a competent. ierminally ill adult who freely requests sucb assistance. This procedure could be earried out by the physician or designee of the physician.

Adult...anyone 18 years of age or over

Terminally ill--prognosis of 6 months or less coofirmed by two physiciane

Competent-oriented to time, place, and person: able to comprebend treatment optoas and ourcomes of these options. 


\section{SITUATION 1:}

You are the nurse who has been caring for Mr. A for the part 2 years. Mr. A is cerminally ill with cancer and has chosen to have bis physician assist bim with dying. The physician is entering the room to administer a drug that will cause Mr. A's death. Mr. A would like for you to be in the room with bim.

Assuming that physician assisted dying for competent, terminally ill patients requesting such assistance is legal:

A. You agree that physician assisted dying is eppropriate, and would go with the physician and stay wich Mr. A while be ieceives the drug and subsequerdly dies.

B. You do NOT agree that physician assisted dying is appropriase BUT would go with the physician and stay with : Mr. A while be receives the drug and subsequently dies because you want to cooperate with the patieat's request.

C. You agree that physician assisted dying is appropriate BUT sould be unable to accompany the physician and stay with Mr. A because of your long term aurse-patient relationsbip with bim.

D. You do NOT agree that physician assisted dying is appropriate and would NOT accompany the physician and stay with Mr. A.

COMMENTS: Are there any comments that you would like to make regarding your choice in this situation?

\section{SITUATION 2:}

Mrs. C. a terminally ill cancer patient you bave never met before, has requested physician assisted deach. She requests that a aurse be in the room with physician when be administers medications to end ber life.

Assuming that physician assisted dying for competent, terminally ill patients requesting such assistance is legal:

A. You agree that physician assisted dying is appropriate and would go with the physician and stay with Mrs. C while she receives medication and subsequendy dies.

B. You do NOT agree that pbysicien assisted dying is appropriate BUT would go with the physician and stay with Mrs. C while she receives the medication and subsequeotly dies because you want to cooperate with the patieat's request.

C. You agree that physician assisted dying is appropriate BUT would be unable to aceompany the physician and stay with Mrs. C even though you bave ao prior aurse-patient relationship with ber.

D. You do NOT agree that pbysician assisted dying is appropriate and would NOT accompany the physician and stay with Mrs. C.

COMMENTS: Are there any commeats that you would like to make regarding your choice in this situation? 


\section{SITUATION 3:}

Mr M. a compecent terminally ill cancer patient, bas requested physician assistance with dying. The physician has written the order for medications to cause his death. Mr. M requests that you now give bim the ordered medication.

Assuming that physician assisted dying for competent, terminally ill patients requesting such assistance is legal:

A. You agree that physician assisted dying is approgriate and would administer the medication to Mr. M.

B. You do NOT agree ibat physician assisted dying is appropriate BUT would administer the medication because you want to cooperate with the patieat's request.

C. You agree hat physician assisted dying is appropriate BUT would be unable to administer the orediczlion to Mr. M.

D. You do NOT agree that paysician assisted dying is appropriate and would NOT administer the medication to Mr. M.

COMMENTS: Are there any comments that you would like to make regarding your choice in this siluation?

\section{SITUATION 4:}

Mrs. W is a competeal terminally ill cancer petieat who requests physician assisted dying. Sbe tells you repeatedly that she "has suffered 100 much, 100 long" and requeses that you be present when medications are administered to assist her dying.

Assuming that physician. assisted dying for competent, terminally ill patients requesting sach assistance is legal:

A. Because profound suffering is a sufficient justiflation for emonination of life you would cooperute wich Mrs. Wr request for playsicisn seristed dyise.

B. Alchough you do NOT believe profound sutfering is sufficient cause for terminxing life, you would still cooperate with Mrs. W/s request for physicien assisted dying.

C. Altbough you believe that profound suffering is sufficient justification for terminating life you would NOT cooperate with Mrs. Frs request for physician assisted dyiog.

D. Because profound sufferiog is NOT a sufficient justification for leminatiog life you would NOT cooperale with Mrs. Wrs request for ptysician assisted dying.

COMMENTS: Are there any comments that you would like to make regarding your choice in this situation? 
INSTRUCTIONS: Please respond to the following questions.

1. Are you familiar with organizations such as:

The Hemlock Society

YES

NO

Americans Against Human Suffering

YES

NO

2. Are you aware that there is proposed legislation in some states that would legalize physician assisted deach for competent, terminally ill adults who request to die?

YES NO

3. Would you vole in favor of legislation that would legalize voluntary, physician assisted deats for competent, terminally ill adults?

COMMENTS:

YES NO

4. To what degree do you feel that the physical pain of terminally ill cancer patients can be controlled? (Circle one response)

4

Effectively

Controlled
3

3

2

Poorty

COMMENTS:

5. Do you believe that cancer patieats you know of receive adequate physical paia relief? (Circle one response)

4

Most of Time
3

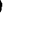

2

Almost never

COMMENTS:

Thank you for completing this questionasire. Please be sure jou have answered each question. Place it in the stamped, addreased return envelope. 


\title{
GRADUATE STUDIES BULLETIN ANNOUNCEMENT
}

\section{Florida International University \\ Division of Graduate Studies}

\section{Master's Thesis Defense}

\author{
Abstract \\ Hospice Nurses' Attitudes on Active Voluntary Euthanasia \\ by
}

Belinda Arjona Godfrey

Active voluntary euthanasia is one of the most controversial issues in the nursing and legal systems today. The purpose of this descriptive study was to explore hospice nurses' attitudes on active voluntary euthanasia ( $A V E$ ). One hundred useable questionnaires were collected, for a response rate of $33 \%$. The questionnaires included demographic data, four vignettes which described a patient care situation and possible responses to $A V E$, questions on awareness of organizations and legislation that promote legalization of $A V E$, and questions on adequate pain relief. The finding revealed fifty - three per cent of the nurses supported AVE. Fifty - four per cent of the nurses would not administer the medication that would cause death. Also, there were significant relationships between the nurses age, religion and educational level and their responses.

Date: November 9, 1995

Department: Nursing

Time: 2:00 PM

Major Professor: Dr. Linda A. Simunek

Place: ACII, North Campus, 230 
October 27, 1995

Belinda Arjona Godfrey, RN, BSN

(305)

Hospice Care Center

Address

FL.

(305) Telephone

Dear Name of Education Director,

I am pleased to notify you that the study (Hospice Nurses Attitude's on Active Voluntary Euthanasia) performed at your hospice center has been completed. I would like to thank you and your staff for all of the cooperation during the study. I will be publishing this study and will notify you of journal and date when aware.

Thank you again,

Very truly yours,

Belinda Arjona Godfrey, RN, BSN 